Urokinase plasminogen activator as an anti-metastasis target: Inhibitor design principles, recent amiloride derivatives and issues with human/mouse species selectivity

Nehad S El Salamouni, ${ }^{\text {a,b,c }}$ Benjamin J Buckley, ${ }^{\text {a,b,c }}$ Marie Ranson, ${ }^{\text {a,b,c }}$ Michael J Kelso, ${ }^{\text {a,b,c,*}}$ and Haibo Yu ${ }^{\text {a,b,c,* }}$

${ }^{a}$ School of Chemistry and Molecular Bioscience, University of Wollongong, NSW 2522, Australia.

${ }^{b}$ Molecular Horizons, University of Wollongong, NSW 2522, Australia.

${ }^{c}$ Illawarra Health and Medical Research Institute, Wollongong, NSW 2522, Australia.

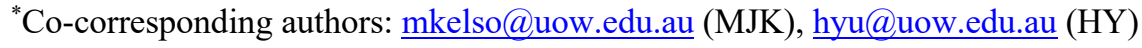

preprint: $\underline{\text { https://osf.io/3z5m4/ }}$

\title{
Keywords
}

Urokinase plasminogen activator, uPA inhibitors, X-ray structures, species selectivity 


\begin{abstract}
The urokinase plasminogen activator (uPA) is a widely studied anticancer drug target with multiple classes of inhibitors reported to date. Many of these inhibitors contain amidine or guanidine groups, while others lacking these groups show improved oral bioavailability. Most of the X-ray co-crystal structures of small molecule uPA inhibitors show a key salt bridge with the side chain carboxylate of Asp189 in the S1 pocket of uPA. This review summarises the different classes of uPA inhibitors, their binding interactions and experimentally measured inhibitory potencies and highlights species selectivity issues with attention to recently described 6-substituted amiloride and 5-N,N-(hexamethylene)amiloride (HMA) derivatives.
\end{abstract}

\title{
The urokinase plasminogen activation system (uPAS)
}

The urokinase plasminogen activation system (uPAS) comprises the trypsin-like serine protease (TLSP) urokinase plasminogen activator (uPA), its cognate cell surface receptor (UPAR) and three endogenous serpin inhibitors, plasminogen activator inhibitors PAI-1, PAI-2 and PAI-3 (Fig. 1) (Andreasen et al. 2000; Croucher et al. 2008; Duffy \& Duggan 2004; Salajegheh 2016; Ulisse et al. 2009). Once activated, uPA converts inactive plasminogen to plasmin, which then triggers downstream activation of multiple proteolytic enzymes such as matrix metalloproteinases (MMPs) and cathepsins (Vassalli et al. 1991). Plasmin, whose activity is regulated by a $a_{2}$-antiplasmin (Hall et al. 1991) can also activate latent growth factors in the extracellular matrix (ECM) (Pedrozo et al. 1999). Under normal physiological conditions, tight control of the activation of these enzymes is required to facilitate the degradation of basement membrane (BM) and remodeling of extracellular matrix (ECM) components in an ordered manner. Increased uPA expression and activity promote tumour cell invasion into surrounding tissues by stimulating the breakdown of BM and ECM (Andreasen et al. 1997; Didiasova et al. 2014; Magill et al. 1999). Dysregulated activity of the uPAS is also implicated in tumour cell proliferation, migration and metastasis (Kugaevskaya et al. 2018; Mahmood et al. 2018; Zhang et al. 2018) and contributes to poor prognosis (Su et al. 2016) and progression in various cancers including melanoma (Cho et al. 2019), hepatocellular carcinoma (HCC) (Wei et al. 2019), lung adenocarcinoma (Zhu et al. 2020), neuroendocrine (Özdirik et al. 2020), oral (Wyganowska-Świątkowska \& Jankun 2015), gastric (Brungs et al. 2017; Kaneko et al. 2003), ovarian (van der Burg et al. 1996), breast (Tang \& Han 2013; Xing \& Rabbani 1996), prostate (Kimura et al. 2020), colorectal (Yang et al. 2000) and bladder cancers (Hasui \& Osada 1997; Iwata et al. 2019). In breast cancer, the uPAS has been identified as the most reliable independent prognostic marker of poor prognosis (Banys-Paluchowski et al. 2019; Bouchet et al. 1994; Duffy et 
al. 1988; Foekens et al. 2000; Harbeck et al. 2002). Small molecule inhibitors of the uPA-uPAR interaction (Bum-Erdene et al. 2020), the uPA protease domain (Buckley et al. 2018; Lee et al. 2004; Rockway et al. 2002) and PAI-1, whose overexpression is also correlated with pro-tumourigenic activity have been developed (Kubala \& DeClerck 2019). In this review, we focus on small molecule inhibitors of the uPA serine protease domain as several studies have revealed that inhibition of uPA-mediated proteolysis can reduce tumour growth and metastasis in rodent models, supporting uPA protease activity as a potential anticancer drug target (Andreasen et al. 2000; Henneke et al. 2010; Matthews et al. 2011a; Ngo et al. 2011; Santibanez 2017; Su et al. 2016; Ulisse et al. 2009). For recent reviews on uPA-uPAR antagonists and PAI-inhibitors see (Yuan et al. 2021) and (Kubala \& DeClerck 2019), respectively.

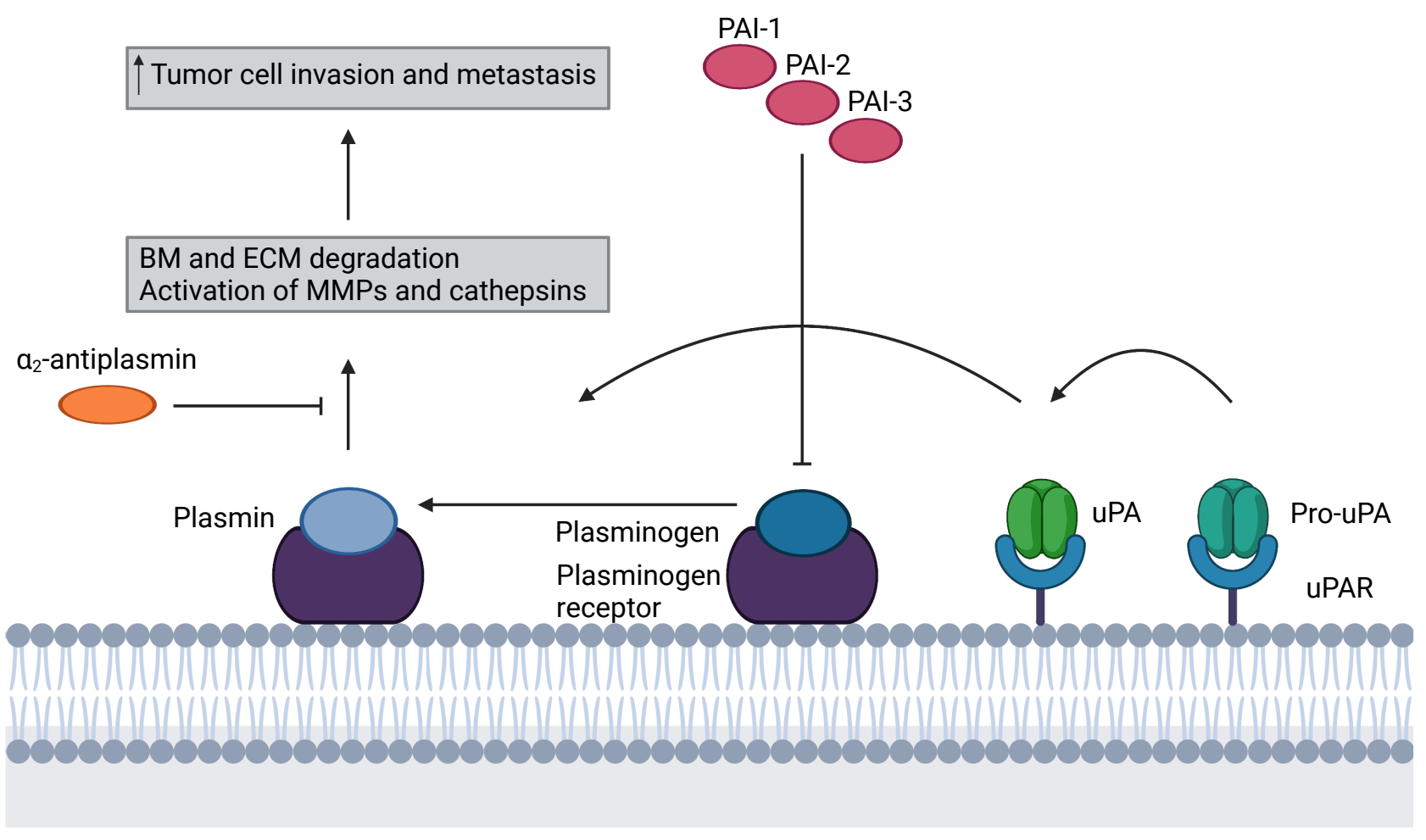

Fig. 1 The urokinase plasminogen activation system (uPAS) in tumour invasion and metastasis. BM: basement membrane, ECM: extracellular matrix, MMPs: matrix metalloproteinases, PAI: plasminogen activator inhibitors, uPAR: urokinase plasminogen activation receptor. Created with BioRender.com.

\section{Structure of uPA}

Human pro-uPA is a $53 \mathrm{kDa}$ single-chain glycoprotein (Wun et al. 1982) consisting of 411 amino acids with glycosylation at Asn302 (Bansal \& Roychoudhury 2006; Lenich et al. 1992), secreted by various normal and tumour cells (Blasi 1988). It comprises an N-terminal growth factor-like domain (residues 1-43) that binds to the cell-surface-anchored uPAR, a central kringle domain (residues 47-135), a common motif observed in related serine proteases (e.g. tissue plasminogen 
activator (tPA) and thrombin) and a C-terminal serine protease catalytic domain (residues 159-411) bearing the catalytic triad His57, Asp102 and Ser195 (numbering after cleavage, Fig. 2) (Spraggon et al. 1995; Stepanova \& Tkachuk 2002). A salt bridge between the side chain amino group of Lys16 and the side chain carboxylate of Asp194 stabilizes the oxyanion hole. Regions comprising the S1 specificity pocket and oxyanion hole are displaced in single-chain pro-uPA, leading to disruption of this salt bridge and explaining its low proteolytic activity (Hedstrom 2002). Cleavage of the Lys158-Ile159 bond by plasmin generates the active, disulfide-linked two-chain high molecular weight (HMW; residues 1-411) uPA (Kasai et al. 1985; Magill et al. 1999; Spraggon et al. 1995). Further cleavage of the Lys135-Ile136 bond in chain A yields soluble, low molecular weight (LMW; residues 136-411) uPA and an amino-terminal fragment (ATF; residues 1-135) (Stepanova \& Tkachuk 2002). HMW and LMW uPA display similar activities towards plasminogen (Sato et al. 2002). Once activated, uPA converts inactive plasminogen into catalytically-active plasmin by hydrolysing its Arg561-Val562 peptide bond (Schuster et al. 2007) after recognising the sequence PGRVV (Ke et al. 1997).

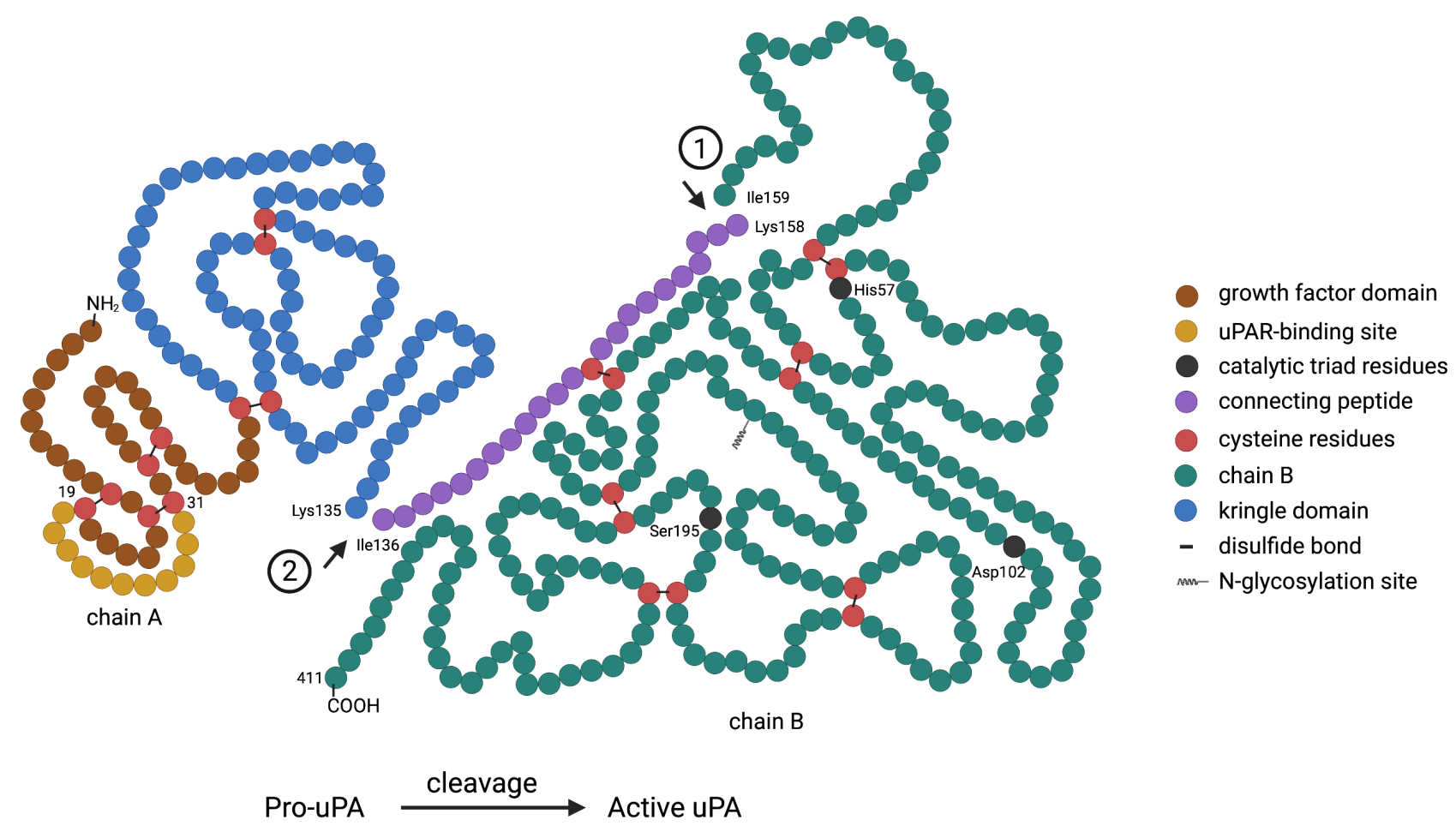

Fig. 2 Schematic representation of uPA. Arrow 1 shows the first cleavage between Lys158 and Ile159 to yield high molecular weight (HMW; residues 1-411) uPA. Arrow 2 shows the second cleavage between Lys135 and Ile136 to yield low molecular weight (LMW; residues 136-411) uPA and the amino-terminal fragment (ATF; residues 1-135). Created with BioRender.com. 


\section{Catalytic mechanism of uPA}

Like other members of the serine protease superfamily, which comprise over one-third of all known proteolytic enzymes,

(Di Cera 2009), uPA hydrolyses peptide bonds after forming a tetrahedral intermediate resulting from the nucleophilic attack of the catalytic Ser195 hydroxyl group on the carbonyl of the substrate scissile amide bond (Fig. 3) (Di Cera 2009; Hunkapiller et al. 1976). Backbone nitrogens of Gly193 and Ser195 line the oxyanion hole that stabilize the negative charge of the tetrahedral intermediate. This is followed by concerted proton transfer, hydrolysis of the intermediate and cleavage of the peptide (Di Cera 2009; Hedstrom 2002; Lee et al. 2004). The S1 pocket controls the catalytic activity (Liu et al. 2012; Spraggon et al. 1995), recognizing basic residues like Arg and Lys in substrate peptides (Rockway et al. 2002). Like many other serine proteases, experimental validation of this mechanism has been provided via mutation of Ser195 to Ala (S195A) (Alipranti et al. 2020; Gong et al. 2016) or Met (S195M) (Masih et al. 2020) to produce catalytically inactive variants.

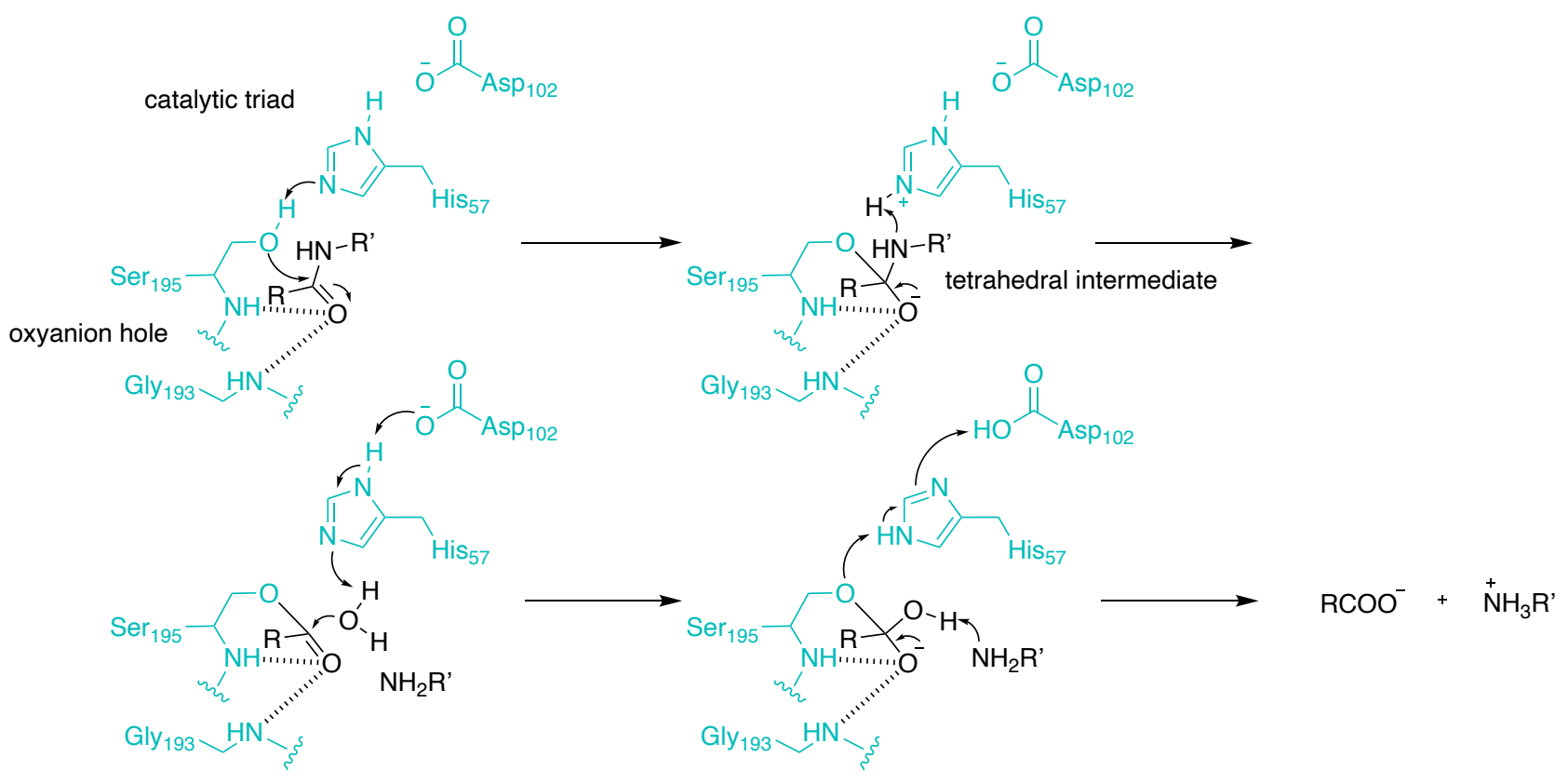

Fig. 3 The catalytic mechanism of serine proteases. Peptide being hydrolysed is shown in black. His57, Asp189 and Ser195 constitute the catalytic triad. The backbone nitrogens of Gly193 and Ser195 comprise the oxyanion hole. uPA residues are shown in cyan.

\section{uPA inhibitors and their binding interactions}

Small molecule uPA inhibitors 
As with other TLSPs, most early uPA inhibitors were arginine-mimetics, comprising an aromatic moiety substituted with an amidine (Klinghofer et al. 2001; Künzel et al. 2002; Mackman et al. 2002; Rudolph et al. 2002; Stürzebecher et al. 1999; Subasinghe et al. 2001) or guanidine (Barber et al. 2004; Fish et al. 2007; Karthikeyan et al. 2009; Sperl et al. 2000) group. These analogues were highly basic $\left(p \mathrm{~K}_{\mathrm{a}}>11\right)$, positively charged at the physiological $p \mathrm{H}$, showed poor pharmacokinetic properties and suffered low oral bioavailability (Rockway et al. 2002). Most inhibitors formed a salt bridge between their amidine/guanidine and the carboxylate of Asp189 located at the base of the arginine-specific S1 pocket (Spencer et al. 2002). A hydrogen bond to residue 190, contributed to selectivity for TLSPs (e.g. uPA, trypsin, Factor VIIa) that have Ser at this position. Other closely related TLSPs (e.g. tPA, thrombin, Factor Xa) have Ala at this position and lack this interaction (Katz et al. 2000). A single atom substitution that caused the displacement of the highly conserved water molecule at the S1 pocket of uPA imparted even more selectivity for Ser190 TLSPs over Ala190 relatives (Katz et al. 2001b; Mackman et al. 2001). This reasoned to be due to interactions with the side chain hydroxyl of the Ser190 that compensated for the displaced water molecule. Many inhibitors partially or fully occupied the S1 $\beta$ pocket (defined by Gln192, Lys143, Ser146 and Gly219 with a disulfide Cys191-Cys220 forming its base, Fig. 4) (Wendt et al. 2004a). Inhibitor uPA selectivity was improved by increasing its occupancy of the S1 $\beta$ subsite, which is absent or much smaller in closely related TLSPs (Nienaber et al. 2000b).

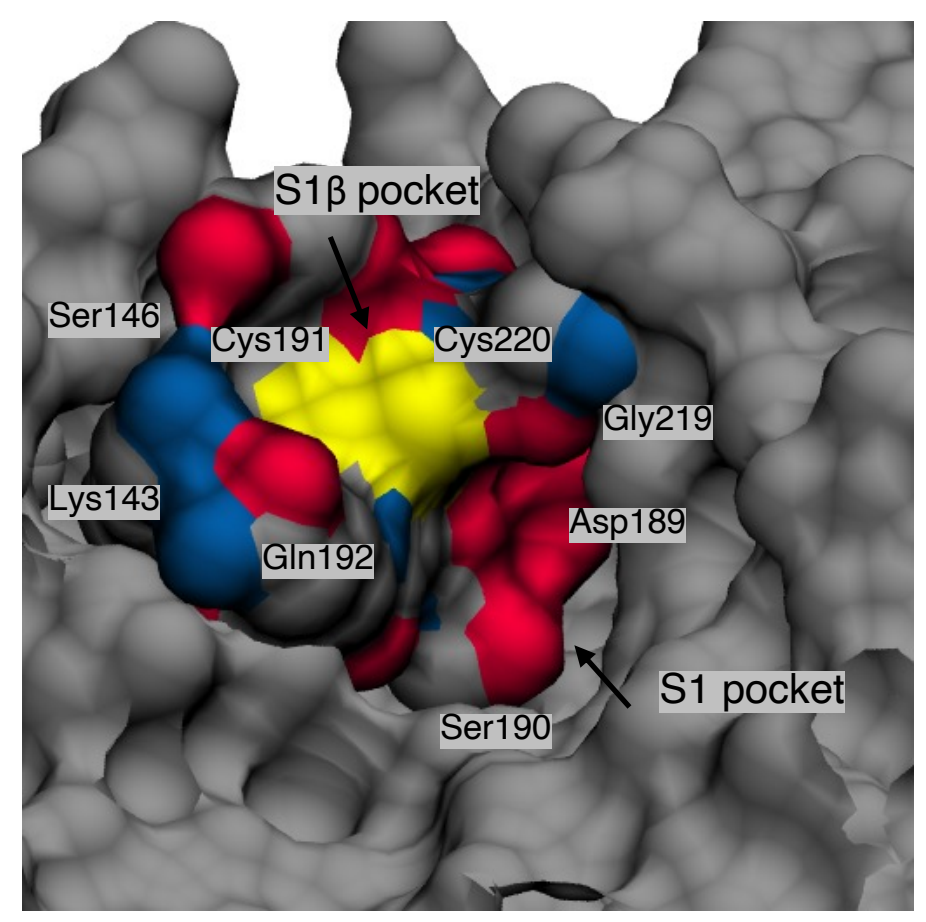

Fig. 4 The uPA binding site showing the $S 1$ and $S 1 \beta$ pockets and their key forming residues. 
Biphenyl amidine $\mathbf{1}$ is a potent and selective uPA inhibitor ( $\mathrm{IC}_{50} 98 \mathrm{nM}$ ) but showed poor oral bioavailability likely due to the basicity of the amidine moiety (West et al. 2009). An X-ray co-crystal structure of the phenyl amidine 2 $\left(K_{\mathrm{i}} 3.8 \mu \mathrm{M}\right)$ bound to uPA (PDB $1 \mathrm{GJA} ; 1.56 \AA$ ) showed the expected salt bridge between the amidine and the side chain carboxylate of Asp189 and a hydrogen bond to the carbonyl of Gly219 (Katz et al. 2001b) (Fig. 5). One of the amidine nitrogens also formed hydrogen bonds to the side chain hydroxyl of Ser190 and a conserved water molecule in the S1 pocket. The phenol group formed two hydrogen bonds with the side chain hydroxyl and backbone nitrogen of Ser195 (Spencer et al. 2002). Benzylsulfonyl- $D$-Ser-Ser-4-amidinobenzylamine $\mathbf{3}$ is a potent and selective uPA inhibitor $\left(K_{\mathrm{i}} 20\right.$ $\mathrm{nM}$ ) that was studied in an experimental model of fibrosarcoma lung metastasis in mice (Schweinitz et al. 2004), which produced robust suppression of metastasis at relatively low dose. Its X-ray co-crystal structure with uPA (PDB 1VJA; $1.56 \AA$ ) showed the salt bridge with Asp189, hydrogen bonds between the sulfonamide and the backbone nitrogen of Gly219 and between one of the hydroxyl groups and the backbone carbonyl of Leu97B, and with the imidazole nitrogen of His99. Interactions of $\mathbf{3}$ with Leu97B and His99 appeared to imparted selectivity for uPA over closely related TLSPs which have different residues at these positions (Schweinitz et al. 2004).

The X-ray co-crystal structure (PDB 1GI8; $1.75 \AA$ ) (Verner et al. 2001) of the potent uPA inhibitor 2-[2hydroxyphenyl]-1H-benzimidazole-5-carboxamidine 4 ( $K_{\mathrm{i}} 8 \mathrm{nM}$ ) (Katz et al. 2001a) showed a unique, multi-centered, strong hydrogen bond network involving its phenolic oxygen, benzimidazole nitrogen, a water molecule and the side chain hydroxyl of Ser195 (Verner et al. 2001). Additional interactions of this ligand with Asp189 were also mediated via a water molecule. The extensive multi-centered hydrogen bonding network prevented the ligand from fully penetrating the S1 pocket and interacting directly with Asp189 (Katz et al. 2001a). One of the amidine nitrogens formed hydrogen bonds to Gly219 while the other hydrogen bonded to the side chain hydroxyl of Ser190 and the backbone carbonyl of Val227 through a water molecule. Introduction of a chlorine atom at the 6-position of the benzimidazole ring displaced the water molecule and improved selectivity over tPA by 220-fold (Katz et al. 2001b). In uPA, the 6-chloro derivative of inhibitor 4 maintained the hydrogen bond between its amidine nitrogen and the side chain hydroxyl of Ser190, however, in the Ala190 protease tPA, this interaction was lost, explaining the marked decrease in activity for this enzyme.

4-Iodobenzo(b)thiophene-2-carboxamidine (B428) 5 is a potent uPA inhibitor $\left(K_{\mathrm{i}} 100 \mathrm{nM}\right)$ that showed high selectivity over tPA and plasmin (Bridges et al. 1993; Klinghofer et al. 2001; Towle et al. 1993). Its X-ray co-crystal structure (PDB 1C5X; $1.75 \AA$ ) (Katz et al. 2000) showed the salt bridge between the amidine and the side chain carboxylate of Asp189, with the iodo group partially occupying the S1 $\beta$ pocket (Klinghofer et al. 2001; Nienaber et al. 
2000a). 2-Naphthamidine $\mathbf{6}$ was used as a starting scaffold for optimisation due to its moderate uPA inhibitory potency $\left(K_{\mathrm{i}} 5.91 \mu \mathrm{M}\right)$ and selectivity (Wendt et al. 2004b). Introduction of a phenyl amide at the 6-position yielded inhibitor 7, which showed a $\sim 10$-fold increase in potency $\left(K_{\mathrm{i}} 631 \mathrm{nM}\right)$ (Wendt et al. 2004b). The X-ray co-crystal structure of 7 (PDB 1OWE; $2.0 \AA$ ) showed the salt bridge between the amidine and Asp189 as well as a hydrogen bond to the side chain hydroxyl of Ser190. The carbonyl of the phenyl amide formed a hydrogen bond with the side chain nitrogen of Gln192, while the nitrogen of the phenyl amide hydrogen bonded to the backbone oxygen of Ser214 via a water molecule (Wendt et al. 2004a; Wendt et al. 2004b). Replacement of the amide moiety with a cyclopropyl group and substitution of the phenyl ring further improved uPA activity $\left(8, K_{\mathrm{i}} 47 \mathrm{nM}\right)$ and delivered oral bioavailability in rats $\left(F_{\text {oral }}=55 \%\right)($ Bruncko et al. 2005). Introduction of substituents at the 8-position of 2-naphthamidine (inhibitors $9 K_{\mathrm{i}} 40 \mathrm{nM}, \mathbf{1 0} K_{\mathrm{i}} 30 \mathrm{nM}$ and $\mathbf{1 1}$ $K_{\mathrm{i}} 0.62 \mathrm{nM}$ ) significantly improved uPA potency via interactions in the S1 $\beta$ pocket, producing the first report of a reversible sub-nM uPA inhibitor (Klinghofer et al. 2001; Nienaber et al. 2000b; Wendt et al. 2004a). Quantum chemical calculations using density functional theory were applied to study interactions of 10 (PDB 1SQO; $1.84 \AA$ ) and 11 (PDB 1SQA; $2.0 \AA$ ) with uPA (Solis-Calero et al. 2018; Wendt et al. 2004a). Both ligands formed the salt bridge between their amidines and Asp189 and hydrogen bonds with Ser190 and Gly219. Their naphthalene cores formed hydrophobic interactions with Cys191, Gln192, Trp215 and Gly216. The aminopyrimidine at the 8-position occupied the S1 $\beta$ subsite, forming hydrophobic $\pi$-sulfur type interactions with the Cys191-Cys220 disulfide. The amide nitrogen in $\mathbf{1 1}$ formed an additional water-mediated hydrogen bond to Ser 214 , its phenyl ring formed $\pi-\pi$ stacking interactions with His 57 and the terminal amino group formed a salt bridge with Asp60A (Solis-Calero et al. 2018).

In 2004, Barber et al. reported that 1-isoquinolinylguanidine analogue UK-356,202 12 (K 37 nM) shows enhanced potency and selectivity for uPA over tPA and plasmin (Barber et al. 2004). Further evolution of the class by Pfizer led to UK-371,804 $13\left(K_{\mathrm{i}} 10 \mathrm{nM}\right)$, which showed high selectivity for uPA over tPA and plasmin (Fish et al. 2007). The compound was shown to inhibit uPA in human chronic wound fluid in vitro $\left(\mathrm{IC}_{50} 890 \mathrm{nM}\right)$ and in a porcine acute excisional wound model in vivo and was selected for further preclinical evaluation as a prospective treatment for chronic dermal ulcers (Fish et al. 2007).

The clinical anticoagulant camostat $\mathbf{1 4}$ acts as a potent broad-spectrum inhibitor of the serine proteases trypsin, plasma kallikrein, FXIa, matriptase and uPA ( $\left.\mathrm{IC}_{50} 87 \mathrm{nM}\right)$ (Sun et al. 2021). The X-ray co-crystal structure of camostat 14 in complex with uPA (PDB 7DZD; $2.00 \AA$ ) showed that it inserts into the S1 pocket and is then hydrolysed to 4- 
guanidinobenzoic acid (GBA), to from a covalent bond with Ser195 in addition to hydrogen bonds between the guanidine moiety and Asp189, Ser190 and Gly219.<smiles>Cc1c(F)c(Oc2cccc(-c3cccc(C(=N)N)c3)c2)nc(Oc2cc(N(C)C)ccc2C(=O)O)c1F</smiles>

1

$\mathrm{IC}_{50} 98 \mathrm{nM}$

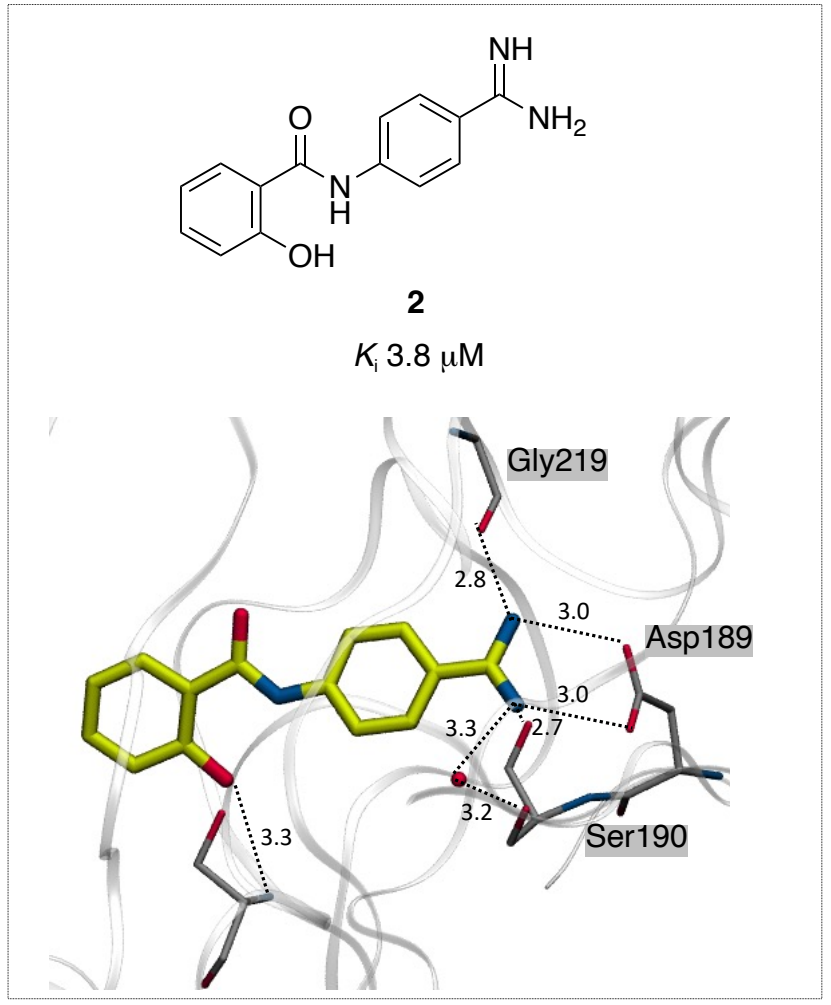<smiles>N=C(N)c1ccc(CNC(=O)[C@H](CO)NC(=O)[C@H](CO)NS(=O)(=O)Cc2ccccc2)cc1</smiles>

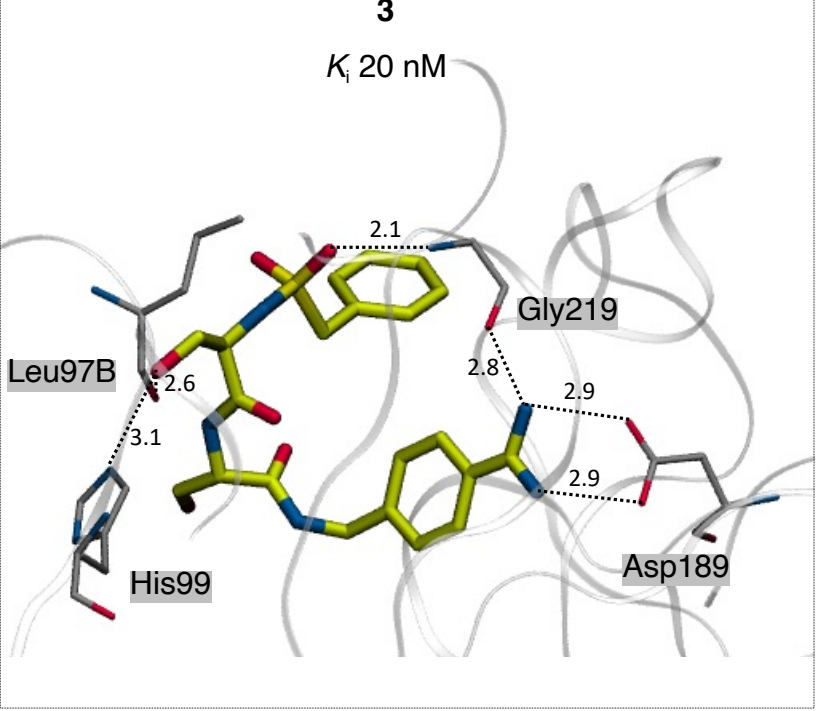



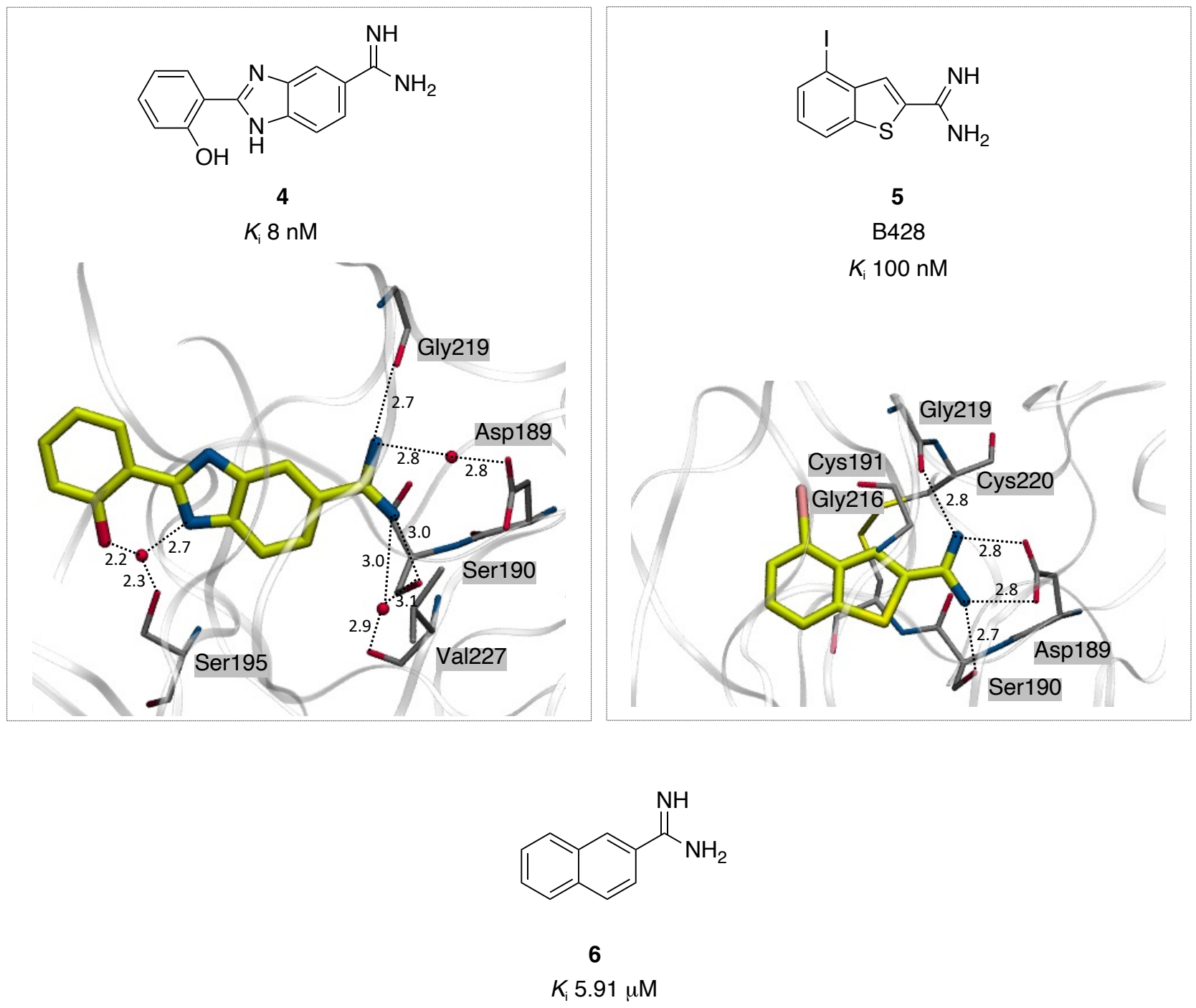<smiles>N=C(N)c1ccc2cc(C(=O)Nc3ccccc3)ccc2c1</smiles>

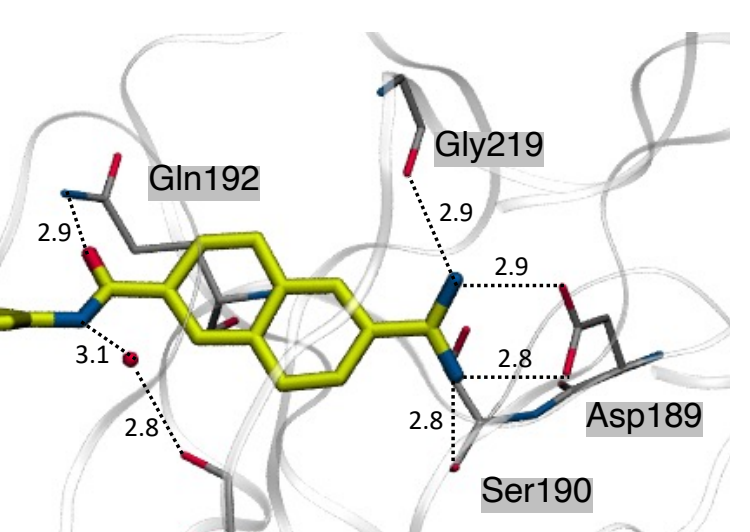

Ser214 
<smiles>CC(C)C1c2cc(C3CC3c3ccc4cc(C(=N)N)ccc4c3)ccc2CCN1C</smiles>

8

$K_{\mathrm{i}} 47 \mathrm{nM}$<smiles>COC(=O)Nc1cccc2ccc(C(=N)N)cc12</smiles>

9

$K_{\mathrm{i}} 40 \mathrm{nM}$
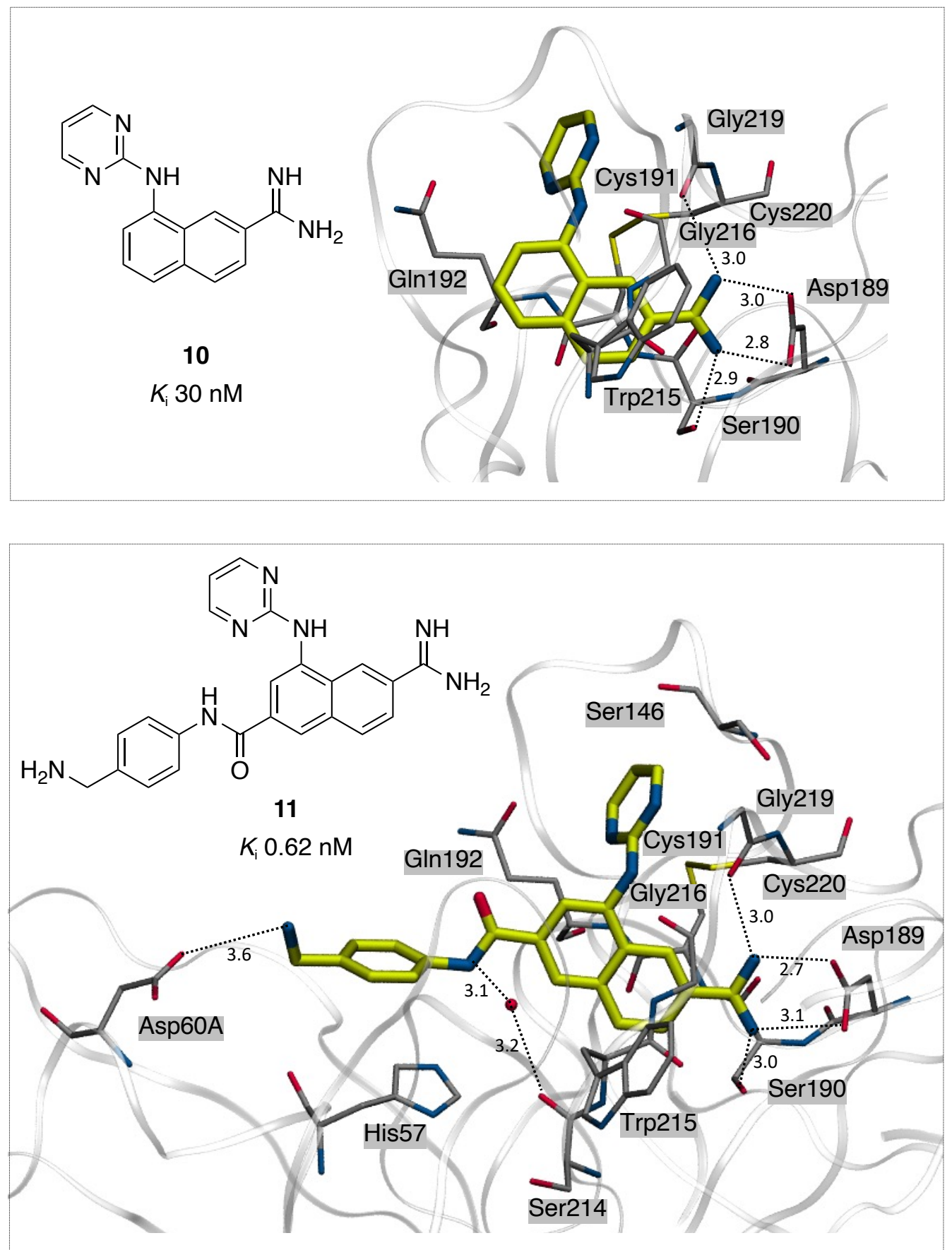
<smiles>NC(N)=Nc1ncc(Cl)c2ccc(-c3ccc(C(=O)O)cc3)cc12</smiles>

12

UK-356,202

$K_{\mathrm{i}} 37 \mathrm{nM}$<smiles>CC(C)(NS(=O)(=O)c1ccc2c(Cl)cnc(N=C(N)N)c2c1)C(=O)O</smiles>

13

UK-371,804

$K_{\mathrm{i}} 10 \mathrm{nM}$

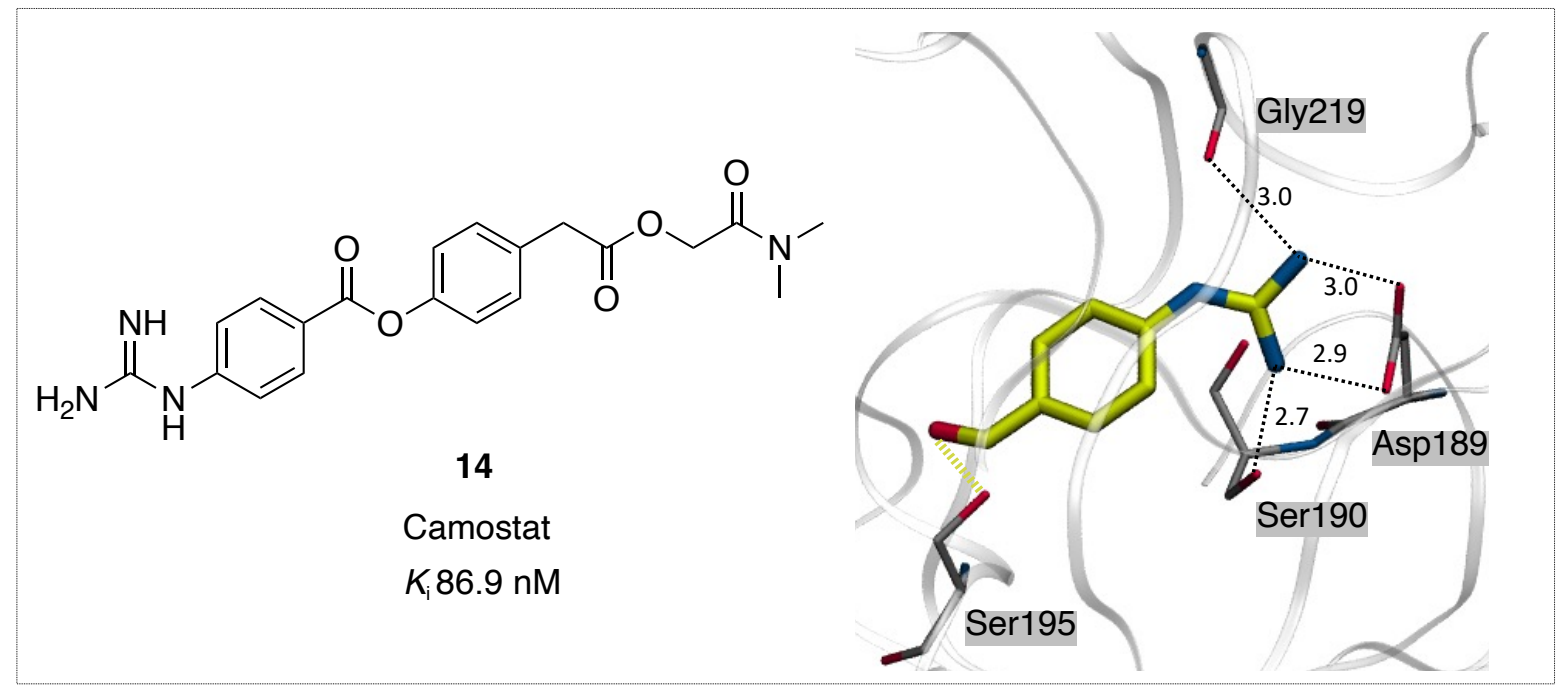

Fig. 5 Amidine and guanidine-based uPA inhibitors 1 - 14. uPA X-ray co-crystal structures of 2, 3, 4, 7, 10, 11 and 14 are shown highlighting the hydrogen bond interactions. Reported $K_{\mathrm{i}} / \mathrm{IC}_{50}$ against human uPA are shown.

6-Substituted analogues of amiloride and 5- $N, N$-(hexamethylene)amiloride (HMA) as uPA inhibitors

Amiloride 15 (Midamor ${ }^{\circledR}$, Fig. 6) is an oral $\mathrm{K}^{+}$-sparing diuretic originally developed in the 1960s (Hirsh et al. 2006). The drug has been clinically used for decades in combination with hydrochlorothiazide (Moduretic ${ }^{\circledR}$ ) or loop diuretics $(e . g$. furosemide, Frumil ${ }^{\circledR}$ ) as an antikaliuretic in patients at risk of hypokalemia during the management of hypertension, heart failure and edema (Vidt 1981). Amiloride's $\mathrm{K}^{+}$-sparing effect is due to selective blockade of renal epithelial sodium channels (ENaCs) in cells of the distal nephron (Warnock et al. 2014). Independent of its renal effects, amiloride has been found to have antimetastatic properties in multiple animal tumour models (reviewed extensively in (Matthews et al. 2011a)).

Amiloride 15 competitively inhibits uPA in a reversible manner $\left(K_{\mathrm{i}} 7 \mu \mathrm{M}\right)$ (Vassalli \& Belin 1987) and does not affect the activity of closely related TLSPs tPA, plasmin, thrombin and kallikrein (Klinghofer et al. 2001). Its moderate potency and high selectivity indicated amiloride as an attractive scaffold for the design of improved small molecule uPA 
inhibitors (Matthews et al. 2011b). Part of amiloride's anticancer effects may also be due to its inhibition of $\mathrm{Na}^{+} / \mathrm{H}^{+}$ exchanger isoforms (NHEs), particularly NHE1; which is a key regulator of intracellular $p$ H. Accordingly, the anticancer/antimetastatic actions of amiloride perhaps arise from dual inhibition of both uPA and NHE1 (Buckley et al. 2021b; Matthews et al. 2011a). Amiloride has excellent drug properties, in part due to its unique acylguanidine group ( $p \mathrm{~K}_{\mathrm{a}} 8.8$, orally bioavailable) (Matthews et al. 2011b), unlike earlier uPA inhibitors that contain basic amidine and guanidine groups $\left(p \mathrm{~K}_{\mathrm{a}}>11\right.$, Fig. 5) that contribute to poor intestinal permeability (Pajouhesh \& Lenz 2005; Rockway \& Giranda 2003).

In the clinic, amiloride's maximum recommended dose is limited to $20 \mathrm{mg}$ /day due to the risks of hyperkalemia and cardiac arrhythmias (Sun \& Sever 2020). In animal models, anticancer/metastasis effects require administration of relatively high doses of amiloride ( $>5 \mathrm{mg} / \mathrm{kg} /$ day), suggesting amiloride is unlikely to produce meaningful anticancer effects when given at safe doses in humans (Buckley et al. 2021a; Matthews et al. 2011a). Thus, Selective Optimisation of a Side Activity (SOSA) approach (Wermuth 2006) represented an attractive strategy to optimise amiloride into a more potent, orally active uPA inhibitor for use in cancer. Matthews et al. prepared several amiloride analogues and showed that the guanidine core, the 2-acylguanidine moiety and the amino groups at the 3-and 5-positions are all essential for uPA inhibitory activity, but no high potency inhibitors were identified in this study (Matthews et al. 2011b). The disruption of uPA-PAI-1 complex by amiloride and its analogues has been modelled using molecular docking simulations (Palsgaard et al. 2018).

Structure-activity relationships for 6-substituted derivatives 5-N,N-(hexamethylene)amiloride (HMA) 17, a well-studied analogue that had shown similar anticancer properties, were reported by (Buckley et al. 2018). HMA 17 is also a more potent NHE1 inhibitor than amiloride 15 (Buckley et al. 2021b; Rich et al. 2000) and showed reduced diuretic effects than amiloride 15 due to weak ENaC activity (Cragoe et al. 1967). 2-Benzofuranyl analogue $16\left(K_{\mathrm{i}} 183 \mathrm{nM}\right)$ demonstrated anti-metastatic properties in a mouse model of metastatic lung cancer (Buckley et al. 2019) and 4methoxypyrimidine analogue $18\left(K_{\mathrm{i}} 53 \mathrm{nM}\right)$ inhibited the formation of liver macrometastases in an orthotopic mouse pancreatic cancer model (Buckley et al. 2018). These effects were attributed to inhibition of uPA as 18 showed 143-fold selectivity for uPA over NHE1 (Buckley et al. 2021b). 
The X-ray co-crystal structures of amiloride 15 (PDB 1F5L; $2.1 \AA \AA$ ) (Zeslawska et al. 2000), HMA 17 (PDB 5ZA7; $1.7 \AA$ ) (Buckley et al. 2018) and 6-substituted analogues 16 (PDB 6AG9; $1.6 \AA$ ) (Buckley et al. 2019) and 18 (PDB 5ZAH; $2.98 \AA$ ) (Buckley et al. 2018) bound to uPA all showed the key salt bridge between the terminal nitrogens of the acylguanidine and the side chain carboxylate of Asp189 as well as hydrogen bonds to the backbone carbonyl of Gly219 and side chain hydroxyl of Ser190. The amide-like NH of the acylguanidine formed a hydrogen bond to the carbonyl of Gly219. A water-mediated hydrogen bond network is present involving a terminal nitrogen and the carbonyl atoms of the acylguanidine and the backbone amide NH and carbonyl oxygen of Val227 and amide NH of Ser214 and the terminal hydroxyl of Ser190. This water molecule is missing in the X-ray co-crystal structure of inhibitor 18 (PDB 5ZAH; $2.98 \AA$ ) (Buckley et al. 2018), however, MD simulations revealed a water molecule from the bulk enters the S1 pocket to form hydrogen bonds with Ser214 and Val227 (El Salamouni et al. 2021). The exocyclic amine at the pyrazine 3-position formed a hydrogen bond to the side chain hydroxyl of Ser195. The chlorine at the pyrazine 6-position of amiloride 15 and HMA 17 interacted with the Cys191-Cys220 disulfide and residues, Gln192, Gly216 and Gly219, which together with Lys143 and Ser146 formed the small hydrophobic S1 $\beta$ subsite (Zeslawska et al. 2000). The substituents at the 6-position of the inhibitors (e.g. 16 and 18) were all oriented towards the S1 $\beta$ subsite. In the presence of the 4methoxypyrimidine inhibitor 18, the side chain of Arg217 flipped towards the S1 $\beta$ pocket forming favourable interactions with the pyrimidine nitrogen (Buckley et al. 2018). Hence, increased uPA inhibitory potency of 6-substituted amiloride and HMA analogues (relative to amiloride 15 and HMA 17) was attributed to the formation of favourable contacts between the 6-substituents and the S1 $\beta$ subsite (Buckley et al. 2018; Matthews et al. 2011a). The interactions in the S1 $\beta$ subsite were also thought to enhance selectivity over other TLSPs due to the absence of corresponding pockets in most related proteases (Buckley et al. 2018). 

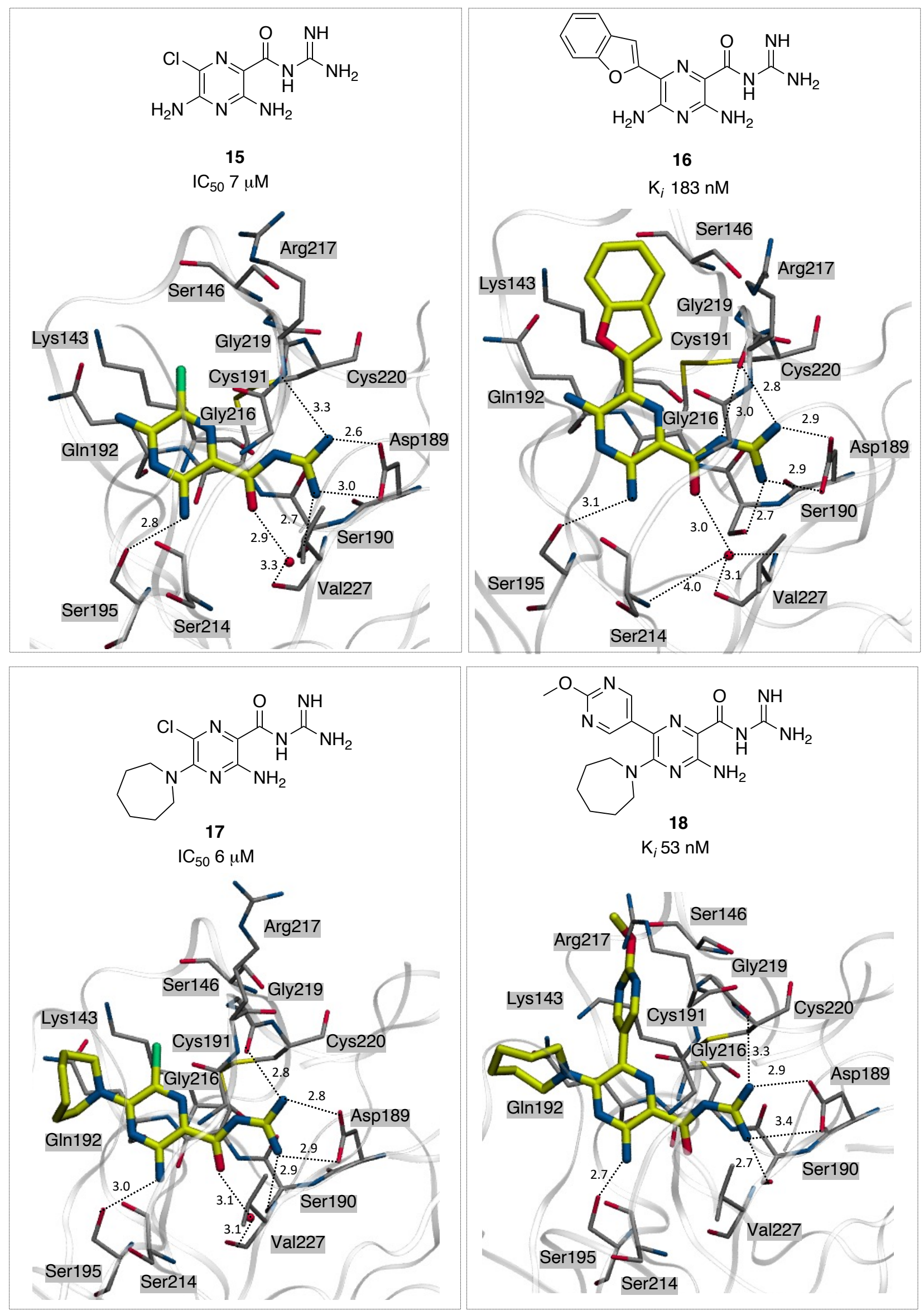

Fig. 6 uPA inhibitors amiloride 15, HMA 17 and 6-substituted analogues 16 and 18 and their uPA X-ray co-crystal structures showing key hydrogen bond interactions. Reported $K_{\mathrm{i}} / \mathrm{IC}_{50}$ against human uPA are shown. 


\section{Non-amidine and guanidine-based uPA inhibitors}

There have been several efforts to design potent, selective and orally bioavailable uPA inhibitors that substitute amidine and guanidine moieties of uPA inhibitors with less basic functional groups that maintain key interactions with Asp189 (Venkatraj et al. 2012). Tranexamic acid (TXA) 19 is an antifibrinolytic (McCormack 2012) and weak active site inhibitor of uPA ( $K_{\mathrm{i}} 2 \mathrm{mM}$, Fig. 7) (Wu et al. 2019). Its uPA X-ray co-crystal structure (PDB 6NMB; $2.30 \AA$ ) showed that the compound binds in the S1 pocket and forms hydrogen bonds with the side chain carbonyl of Asp189, the backbone carbonyl of Ser190 and side chain hydroxyl of Ser195. Hydrophobic interactions were formed between the cyclohexane ring and two cysteines (Cys191 and Cys219) as well as with Gly216 (Wu et al. 2019). YO-2 20 (IC50 $3.99 \mu$ M) and PSI$11221\left(\mathrm{IC}_{50}>25 \mu \mathrm{M}\right)$ are derivatives of TXA 19 that inhibited uPA in the micromolar range (Law et al. 2017; Tsuda et al. 2021). YO-2 20 is more active than PSI-112 21 due to interaction of Tyr60 in uPA with the pyridine ring of YO-2 20, while it seemed to sterically clash with the quinoline moiety in PSI-112 21 together with the side chain of Arg35. PSI112 is more selective for plasmin over uPA with Phe587 acting as a key residue in plasmin for the binding of these inhibitors. Loss of interactions with the equivalent residue Val41 in uPA was thought to explain this selectivity (Law et al. 2017).

Optimization of earlier inhibitor 1 (Fig. 5) led to 22 (PDB 3IG6; $1.83 \AA$ ), a more potent (IC50 25 nM, Fig. 7) and selective inhibitor of uPA that maintained the salt bridge with Asp189 via a primary amino group (West et al. 2009). The amine also formed hydrogen bonds with the backbone carbonyls of Ser190 and Gly218. The carboxylic acid moiety formed hydrogen bonds to the side chain imidazole and hydroxyl of the catalytic His57 and Ser195, respectively, as well as the backbone nitrogen of Gly193. Despite this, the compound showed no oral bioavailability due to the additional basic dimethylamino pyrrolidine. However, the truncated derivative ZK824859 23 ( $\left.\mathrm{IC}_{50} 79 \mathrm{nM}\right)$ showed acceptable oral bioavailability in rats $\left(F_{\text {oral }}=30 \%\right)$ (Islam et al. 2018). A model structure of compound 23 based on the X-ray co-crystal structure of 22 showed that it maintains the salt bridge interaction with Asp189, forms hydrogen bonds between its primary amine and the backbone carbonyls of Ser190 and Gly218 and between its carboxylic acid and the side chain imidazole of His57, backbone nitrogen of Gly193 and the side chain hydroxyl of Ser195 (Islam et al. 2018). Selectivity of ZK824859 23 for uPA over tPA was attributed to the positioning of the difluoropyridine ring close to His99, as residue 99 in tPA is Tyr, which could sterically clash with a fluorine atom (Islam et al. 2018). 2-Amino-5-hydroxybenzimidazole $24\left(p \mathrm{~K}_{\mathrm{a}}\right.$ 7.4) showed moderate activity against uPA ( $\left.\mathrm{IC}_{50} 10 \mu \mathrm{M}\right)$ (Hajduk et al. 2000) and its uPA X-ray co-crystal structure (PDB 1FV9; $3.00 \AA$ ) showed a salt bridge between the 2-amino group and Asp189 and hydrogen bonds between the imidazole and Gly218. Replacing the amide linker of naphthamidine inhibitor 11 (Fig. 5) with a sulfonamide and the aryl amidine with a methyl ester yielded 25 (Fig. 7), which retained some uPA potency ( $\left.K_{\mathrm{i}} 2.8 \mu \mathrm{M}\right)$ and maintained selectivity over other TLSPs (Venkatraj et al. 2012). 
4-Bromobenzylamine 26 is a weak inhibitor of uPA $\left(K_{\mathrm{i}} 1.28 \mathrm{mM}\right)$, however, its uPA X-ray co-crystal (PDB 5YC6; $1.18 \AA$ ) revealed that this simple compound buries deeply into the S1 pocket and forms a non-covalent halogen bond between the electron-withdrawing bromine atom and the electron-rich Asp189. The bromine atom also made two interactions with the backbone carbonyl and side chain hydroxyl of Ser190, and van der Waals interactions were seen between its phenyl group and Ser190, Cys191, Gln192, Trp215, Gly216 and Arg217 (Jiang et al. 2018).

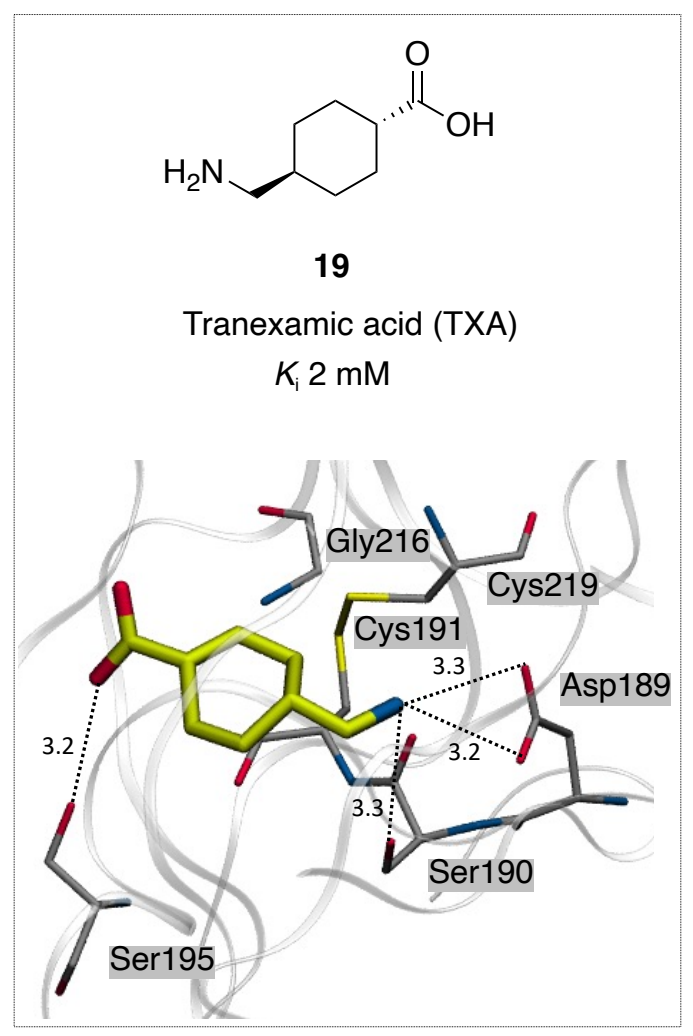<smiles>CCCCCCCCCCCCC(=O)C(Cc1ccc(OCc2ccncc2)cc1)NC(=O)[C@H]1CC[C@H](CN)CC1</smiles>

20

YO-2

$K_{\mathrm{i}} 3.99 \mu \mathrm{M}$<smiles>CCCCCCCCCCCCCCCC(=O)NC(Cc1ccc(OCc2ccc3ccccc3n2)cc1)C(=O)[C@H]1CC[C@H](CN)CC1</smiles>

21

PSI-112

$K_{\mathrm{i}}>25 \mu \mathrm{M}$

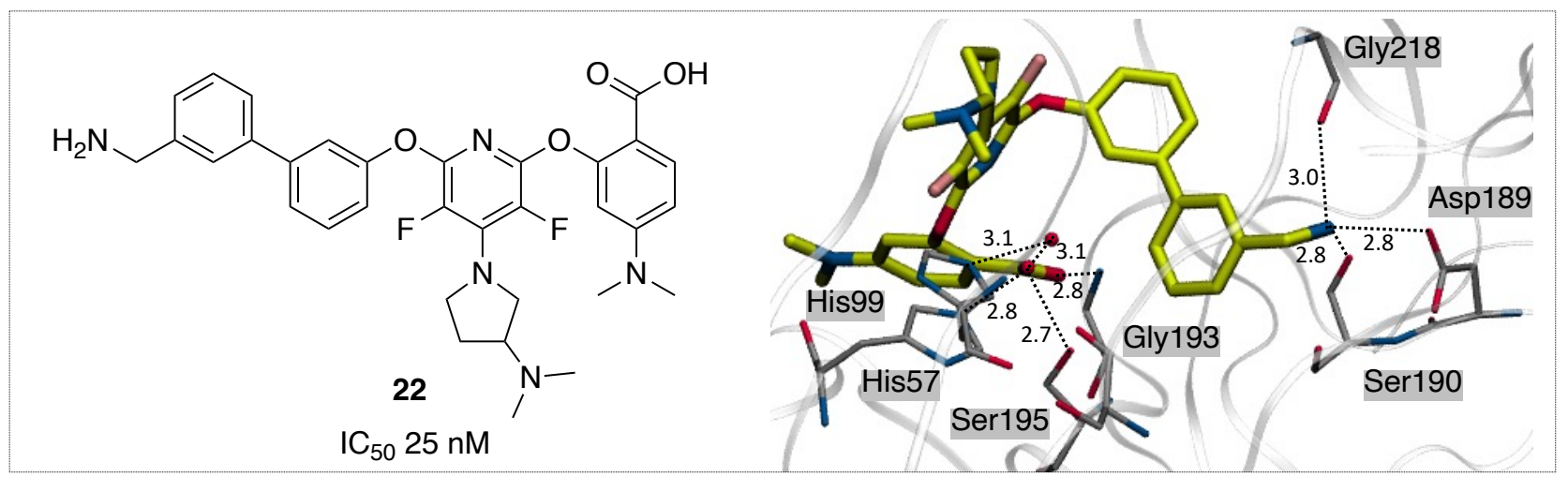


<smiles>CC[C@@H](Oc1nc(Oc2cc(C)cc(-c3cccc(CN)c3)c2)c(F)cc1F)C(=O)O</smiles>

23

ZK824859

$\mathrm{IC}_{50} 79 \mathrm{nM}$<smiles></smiles>

$\mathrm{HO}$<smiles>Nc1nc2ccccc2[nH]1</smiles>

24

$\mathrm{IC}_{50} 10 \mu \mathrm{M}$

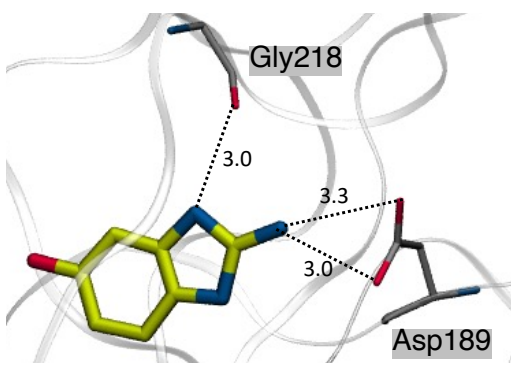

Asp189

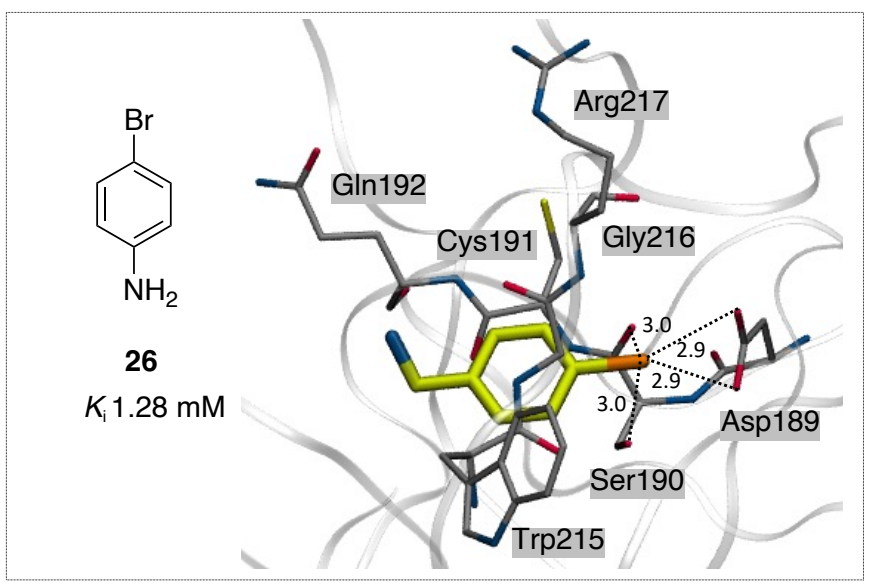

Fig. 7 Non-amidine and guanidine-based uPA inhibitors 19-26. X-ray co-crystal structures of 19, 22, 24 and 26 showing key binding interactions. Reported $K_{\mathrm{i}} / \mathrm{IC}_{50}$ against human $\mathrm{uPA}$ are shown.

\section{Clinical studies with uPA inhibitors}

The first and most advanced uPA inhibitor in oncology studies was the oral small molecule antimetastatic and noncytotoxic 3-amidinophenylalanine WX-UK1 (Mesupron ${ }^{\circledR}$ ) 27 and its hydroxyamidine prodrug WX-671 28 (Fig. 8), both developed by WILEX AG, Germany (Fathi et al. 2019). Mesupron ${ }^{\circledR} 27$ successfully completed several phase I(Goldstein 2008) and II clinical trials in pancreatic and breast cancer. In 2014, RedHill Biopharma acquired the exclusive worldwide development and commercialization rights to Mesupron ${ }^{\circledR} 27$ for all indications (Banys-Paluchowski et al. 2019). Mesupron $^{\circledR} 27$ is a modest uPA inhibitor $\left(K_{\mathrm{i}} 410 \mathrm{nM}\right)$ (Stürzebecher et al. 1999) but is non-selective and inhibits closely related TLSPs (Setyono-Han et al. 2005; Xu et al. 2017). The amidine moiety of Mesupron ${ }^{\circledR}$ prodrug WX-671 28 inserts into the S1 pocket of uPA to form the salt bridge with Asp189 with the rest of molecule interacting with residues in 216218 and 99 loops (Fathi et al. 2019). It was recently found that WX-UK1 27 is a nanomolar inhibitor of the human serine proteases trypsin-6, trypsin-3, trypsin-2, trypsin-1 and matriptase-1 (Oldenburg et al. 2018). As such, it is unclear to what 
extent the clinical efficacy reported for Mesupron ${ }^{\circledR}$ is attributable to uPA inhibition over its more potent effects on other cancer-relevant proteases.

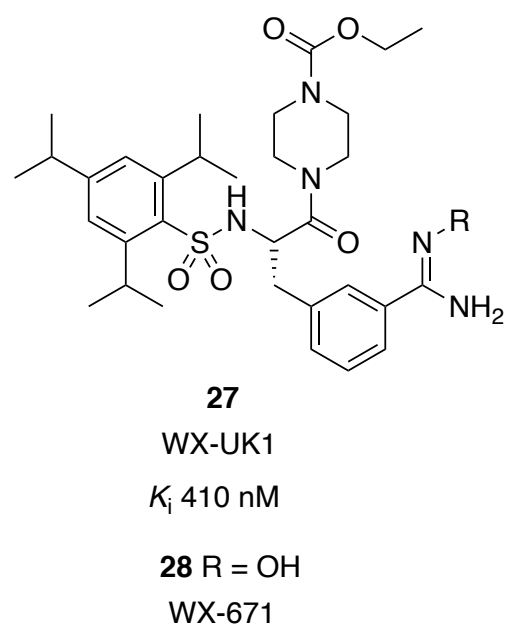

Fig. 8 Clinical uPA inhibitors WX-UK1 $\left(\right.$ Mesupron $\left.^{\circledR}\right) 27$ and its hydroxyamidine prodrug WX-671 28. Reported $K_{\mathrm{i}}$ against human uPA are shown.

\section{Ligand-based design of UPA inhibitors}

Using seven diverse sets of inhibitors, the pharmacophoric space of $202 \mathrm{uPA}$ inhibitors was explored and three high quality models were developed showing binding interactions comparable to those seen in the crystal structures of inhibitors bound to uPA (Al-Sha'er et al. 2014). This was followed by quantitative structure activity relationship (QSAR) analysis, where using the pharmacophoric models and QSAR equation to screen the National Cancer Institute (NCI) libraries identified four hits $\mathbf{2 9}$ - 32 that showed moderate potency against uPA (IC $506.3-28.4 \mu \mathrm{M}$, Fig. 9).

\section{Fragment-based discovery of uPA inhibitors}

Fragment based drug discovery (FBDD) uses low molecular weight compounds (fragments), selected based on their ability to bind to the target as starting points for hit to lead optimization (Denis et al. 2021; Giordanetto et al. 2019). Using FBDD, the oral antiarrhythmic drug, mexiletine $33\left(\mathrm{IC}_{50}>1 \mathrm{mM}\right)$, a fragment hit from X-ray crystallographic screening against $\mathrm{uPA}$, was selected as a starting fragment for optimisation. The program delivered compound $\mathbf{3 4}$ as a potent (IC $\mathrm{I}_{50}$ $72 \mathrm{nM})$, selective, weakly basic $\left(p \mathrm{~K}_{\mathrm{a}} 8.7\right)$ and orally bioavailable $\left(F_{\text {oral }}=60 \%\right)$ uPA inhibitor (Frederickson et al. 2008). While the X-ray co-crystal structure of mexiletine 33 (PDB 2VIN; $1.90 \AA$ ) did show the salt bridge between its amine and Asp189, as well as hydrogen bonds to the backbone carbonyls of Ser190 and Gly219, these interactions were weaker with the more potent derivative 34 (PDB 2VIW; $2.05 \AA$ ). Instead, water-mediated hydrogen bonds were formed between 
the amide carbonyl of $\mathbf{3 4}$ and the side chain imidazole nitrogen of His99 and the backbone carbonyl of Ser214. Amide substituted imidazo[1,2-a]pyridine analogues e.g. 35 that showed high uPA potency ( $\left.\mathrm{IC}_{50} 97 \mathrm{nM}\right)$ and greater than 1000 fold selectivity over other TLSPs were developed from an imidazopyridine starting scaffold (Gladysz et al. 2015). Docking of these analogues showed the common hydrogen bonds with Asp189, Ser190, Ser195, Gly219 and an additional hydrogen bond between the amide NH and Tyr151.<smiles>COc1ccc(S(C)(=O)=O)cc1NC(=O)CCc1ccc(N2C(N)=NC(N)=NC2(C)C)cc1Cl</smiles><smiles>CC(C)CNC(=O)CCc1cccc2c1oc1c(CCN)cccc12</smiles>

$\mathrm{NCl} 0135766$

30

$\mathrm{NCl0666712}$

$\mathrm{IC}_{50} 6.3 \mu \mathrm{M}$

$\mathrm{IC}_{50} 9.0 \mu \mathrm{M}$<smiles>Cc1ccc(S(=O)(=O)Nc2cccc3c(O)ncnc23)cc1</smiles>

31

$\mathrm{NCl} 004367$

$\mathrm{IC}_{50} 11.3 \mu \mathrm{M}$<smiles>CC1(C)N=C(N)N=C(N)N1c1cccc(CNC(=O)Nc2ccccc2)c1</smiles>

32

$\mathrm{NCl} 0144205$

$\mathrm{IC}_{50} 28.4 \mu \mathrm{M}$<smiles>Cc1cccc(C)c1OCC(C)N</smiles>

33

Mexiletine $\mathrm{IC}_{50}>1 \mathrm{mM}$<smiles></smiles>

34

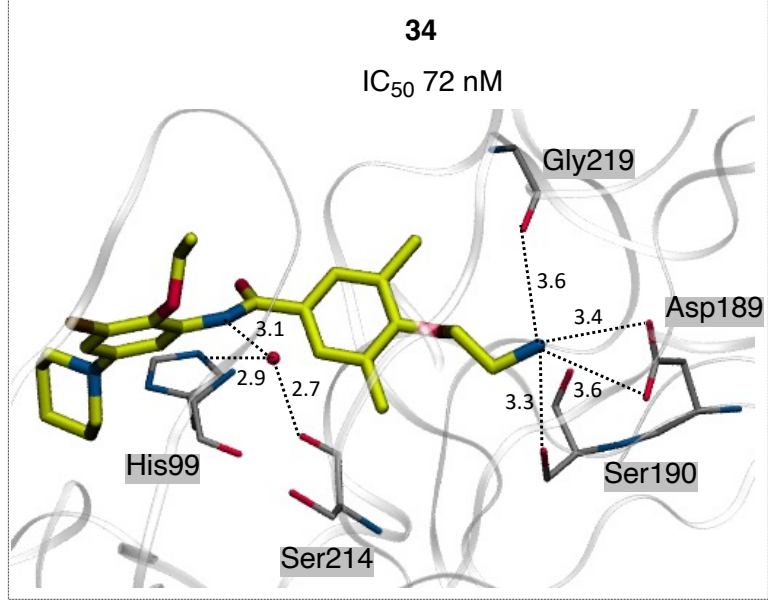

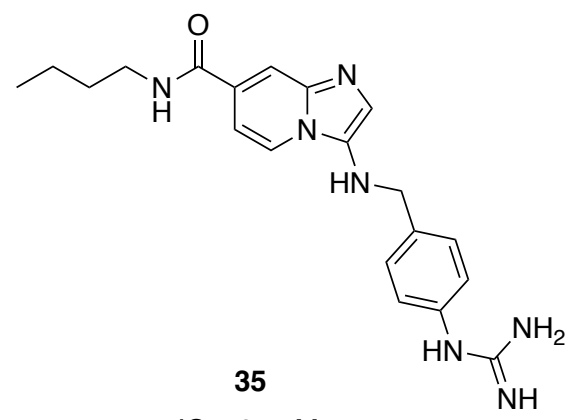

$\mathrm{IC}_{50} 97 \mathrm{nM}$ 
Fig. 9 uPA inhibitors $\mathbf{2 9}$ - 32 identified through screening of NCI libraries, and compounds $\mathbf{3 3}$ - $\mathbf{3 5}$ from fragment-based screening programs. The uPA X-ray co-crystal structure of $\mathbf{3 4}$ showing key hydrogen bond interactions. Reported $K_{\mathrm{i}} /$ $\mathrm{IC}_{50}$ against human $\mathrm{UPA}$ are shown.

\section{Structure-based design of uPA inhibitors}

Until the mid-1990s, no crystallographic information existed on full length, single or two chain uPA, precluding structurebased drug design (SBDD) programs (Spraggon et al. 1995; Zeslawska et al. 2000). In 1995, Spraggon et al. reported the first X-ray co-crystal structure of the catalytic domain of human uPA complexed with the irreversible inhibitor Glu-GlyArg chloromethyl ketone (EGR-cmk 36, Fig. 10). The structure revealed that the enzyme has an S1 specificity pocket similar to trypsin, a less accessible hydrophobic S2 pocket and a solvent-accessible S3 pocket capable of accommodating a wide range of amino acids (Spraggon et al. 1995). The arginine moiety in EGR-cmk 36 bound to Asp189 in the S1 pocket, with one of the guanidine nitrogens hydrogen bonding to the side chain hydroxyl of Ser190 and the backbone carbonyl of Gly218. A salt bridge and a hydrogen bond were formed between the glutamate in EGR-cmk 36 and Arg217 and Glu218, respectively (Spraggon et al. 1995).

In 2000, Zeslawska et al. reported the X-ray co-crystal structure of a novel truncated variant of human uPA in complex with amidinophenylalanine derivative UKI-1D 37 (PDB 1F92, $2.6 \AA$, $K_{\mathrm{i}} 640 \mathrm{nM}$ ) (Zeslawska et al. 2000). This structure showed that the amidine buried deeply into the S1 pocket to form the salt bridge with Asp189. The amidine also formed hydrogen bonds with the backbone carbonyls of Ser190 and Gly219. The alanine nitrogen was directed away from His99 and a hydrogen bond was present between the nitrogen of the terminal amine group and Tyr94. Hydrophobic van der Waals interactions were formed with His57, Leu97B, His99 and Trp215.

In the same year, Sperl et al. reported the X-ray co-crystal structure of human uPA complexed with $N$-(1adamantyl)-N'-(4-guanidinobenzyl)urea WX-293T 38 (PDB 1EJN; $1.8 \AA$ ) ( $\left.K_{\mathrm{i}} 2.4 \mu \mathrm{M}\right)$ (Sperl et al. 2000). The phenylguanidine moiety inserted into the S1 specificity pocket and formed the salt bridge with Asp189. Hydrogen bonds were formed with Ser190, Gly193, Ser195 and Gly219. The ureido group made new interactions with the hydrophobic S1' subsite, comprising the Cys58-Cys42 disulfide and the backbone carbonyls of Val41 and His57 (Sperl et al. 2000 ; Zeslawska et al. 2000). 
Molecular docking of uPA inhibitor UK122 $39\left(K_{\mathrm{i}} 640 \mathrm{nM}\right)$ showed the phenylamidine moiety forming the salt bridge to Asp189 and hydrogen bonds to Ser190 in the S1 pocket (Zhu et al. 2007). The oxazolidinone moiety formed hydrogen bonds with His99, Asp194, Ser195 and Gly198. UK122 39 inhibited migration and invasion of CFPAC-1 pancreatic cancer cells in vitro (Zhu et al. 2007).

In 2014, Sa et al. studied the uPA binding modes of five 1-(7-sulfonamidoisoquinolinyl)guanidine inhibitors 40 - 44 using binding free energy calculations with the Molecular Mechanics / Poisson-Boltzmann Surface Area (MM/PBSA) method (Sa et al. 2014). The calculated free energies were consistent with earlier experimentally-determined values (Fish et al. 2007). For the five uPA inhibitor complexes, a Molecular Mechanics / Generalized Born Surface Area (MM/GBSA) free energy decomposition analysis revealed that Asp189 makes the most favourable contribution to the binding free energy, followed by Ser190, Cys191 and Gln192, along with Trp215, Gly216, Arg 217, Gly218 and Cys 219 (Sa et al. 2014). 

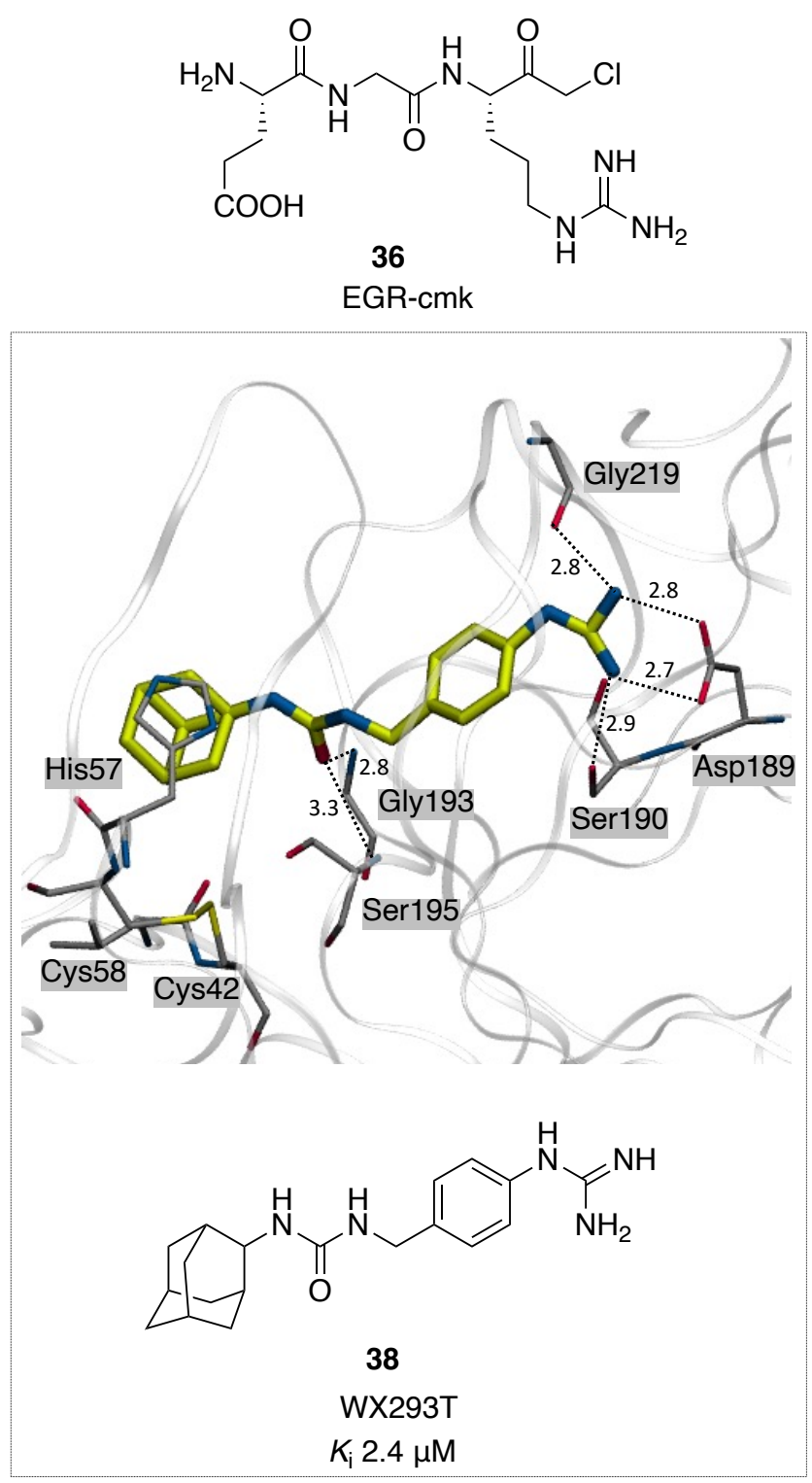
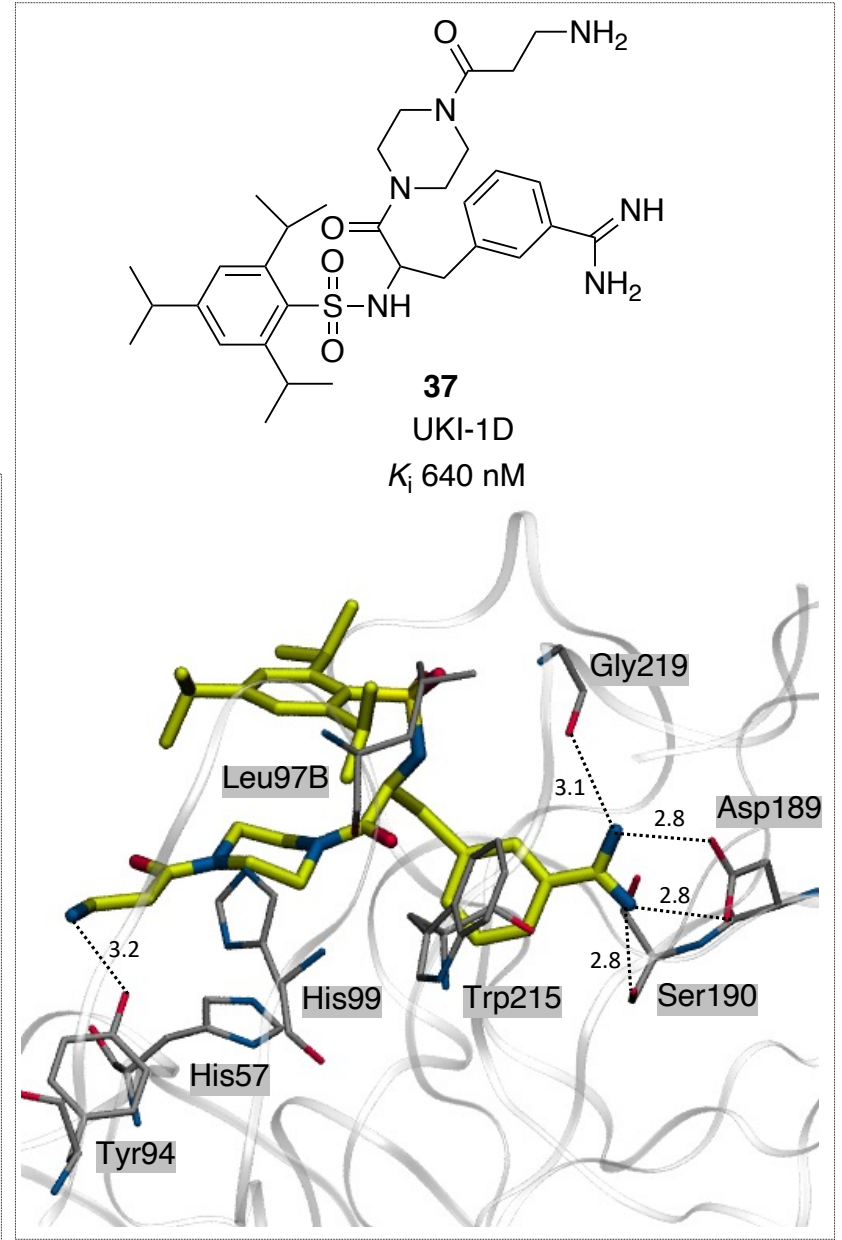<smiles>N=C(N)c1ccc(/C=C2/N=C(c3ccccc3)OC2=O)cc1</smiles>

39

UK122

$K_{\mathrm{i}} 640 \mathrm{nM}$<smiles>NC(N)=Nc1nccc2ccc(S(=O)(=O)Nc3ccccc3)cc12</smiles>

40

$K_{\mathrm{i}} 160 \mathrm{nM}$<smiles>NC(N)=Nc1ncc(Cl)c2ccc(S(=O)(=O)NCC(=O)O)cc12</smiles>

41

$K_{\mathrm{i}} 48 \mathrm{nM}$<smiles></smiles>

42

$K_{\mathrm{i}} 10 \mathrm{nM}$ 


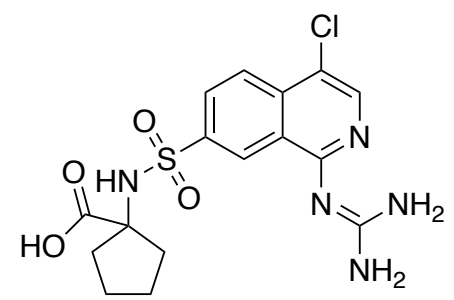

43

$K_{\mathrm{i}} 11 \mathrm{nM}$<smiles>CN(C)CCN(C1(C(=O)O)CCCC1)S(=O)(=O)c1ccc2c(Cl)cnc(N=C(N)N)c2c1</smiles>

44

$K_{\mathrm{i}} 2.6 \mathrm{nM}$

Fig. 10 Chemical structures of inhibitors $36-44$ and X-ray co-crystal structures of 37 and 38 showing key interactions with uPA. Reported $K_{\mathrm{i}}$ against human uPA are shown.

\section{Cyclic peptide uPA inhibitors}

The design of peptides that target serine proteases has attracted much interest (Li et al. 2019) and several disulfide-bridged cyclic peptide uPA inhibitors have been developed (Fig. 11). Upain-1 45 (CSWRGLENHRMC, $K_{\mathrm{i}} 500 \mathrm{nM}$ ) is a highly specific competitive inhibitor of human uPA (Hansen et al. 2005). An X-ray co-crystal structure of upain-1 45 bound to uPA (PDB 2NWN, $2.15 \AA$ ) showed direct interactions with Arg35, His57, Asp60A, Tyr64, His99, Asp189, Ser190, Gln192, Gly193, Ser195, Gly216 and Gly219. A pair of water-mediated interactions were present between two conserved water molecules and residues Gly216, Gly219, Ile60 and Asp60A (Zhao et al. 2007). Upain-1 45 also extensively interacted with residues comprising 37- and 60-loops as well as His99. These residues are significantly different in human and mouse uPA and in related TLSPs (Zhao et al. 2007), which imparted selectivity of upain-1 45 for human uPA. Alanine scanning of residues Asp57, Asp60A, Tyr94, His99, Tyr151, Trp186, Asp189 and Trp215 produced 10-fold reductions in binding affinity (Hansen et al. 2005). Upain-1-W3F mutant 46 (CSFRGLENHRMC, PDB 6XVD 1.40 $\AA$ ) was found to be a weaker uPA inhibitor $\left(K_{\mathrm{i}} 149 \mu \mathrm{M}\right)$ (Xue et al. 2020).

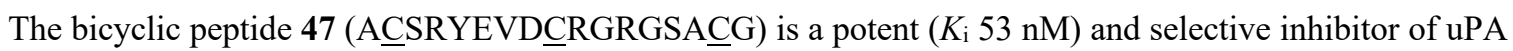
(Angelini et al. 2012). The presence of two small, constrained loops rather than a single loop proffered multiple improved interactions with uPA. The uPA X-ray co-crystal structure of 47 (PDB 3QN7, $1.90 \AA$ ) showed hydrogen bonds with His57, Asp60A, Tyr60B, Val141, Gln192, Gly193, Asp189, Ser190, Ser195 and Gly218. Close contacts (distances < 4 A) with Arg35, His37, Arg37A, Thr39, Gly37B, His99, Tyr151, Asp194, Lys224, Pro225 and Gly226 were also observed. 
With an absence of specific inhibitors of mouse uPA for use in mouse cancer models, cyclic peptide inhibitor mupain-1 48 (ㄹAYSRYLDĆ, $K_{\mathrm{i}} 500 \mathrm{nM}$ ) was designed to target mouse uPA (Andersen et al. 2008; Zhao et al. 2014). A three-dimensional model of mupain-1 $\mathbf{4 8}$ at the binding site of mouse uPA showed interactions with Lys41, His57, Tyr99, Ser195, Asp189 and Lys192 (Andersen et al. 2008). His99 in human uPA is important for imparting selectivity of upain-1 45 and Tyr99 in mouse uPA for mupain-1 48 (Zhao et al. 2007). Substituting His99 in human uPA to Tyr99 (as in mouse uPA), led to a 100-fold increase in affinity for human uPA (Andersen et al. 2008). The X-ray co-crystal structure of the partially murinised human uPA (H99Y) in complex to mupain-1 48 (PDB 4X1Q, $2.28 \AA$ ) revealed interactions with Arg35, Cys58, Thr97A, Leu97B, Tyr99, Asp189, Ser190, Gln192, Gly193, Arg217 and Gly219 (Zhao et al. 2014). In general, inhibitor binding to uPA resulted in entropic loss, hence increasing the rigidity of the inhibitors improved entropic contributions to binding (Roodbeen et al. 2013; Zhao et al. 2014). In contrast to upain-1 45 and other serine protease inhibitors, increasing the flexibility of mupain-1 48 improved binding affinity for uPA (Xu et al. 2017) due to more favourable exosite interactions (Zhao et al. 2014).

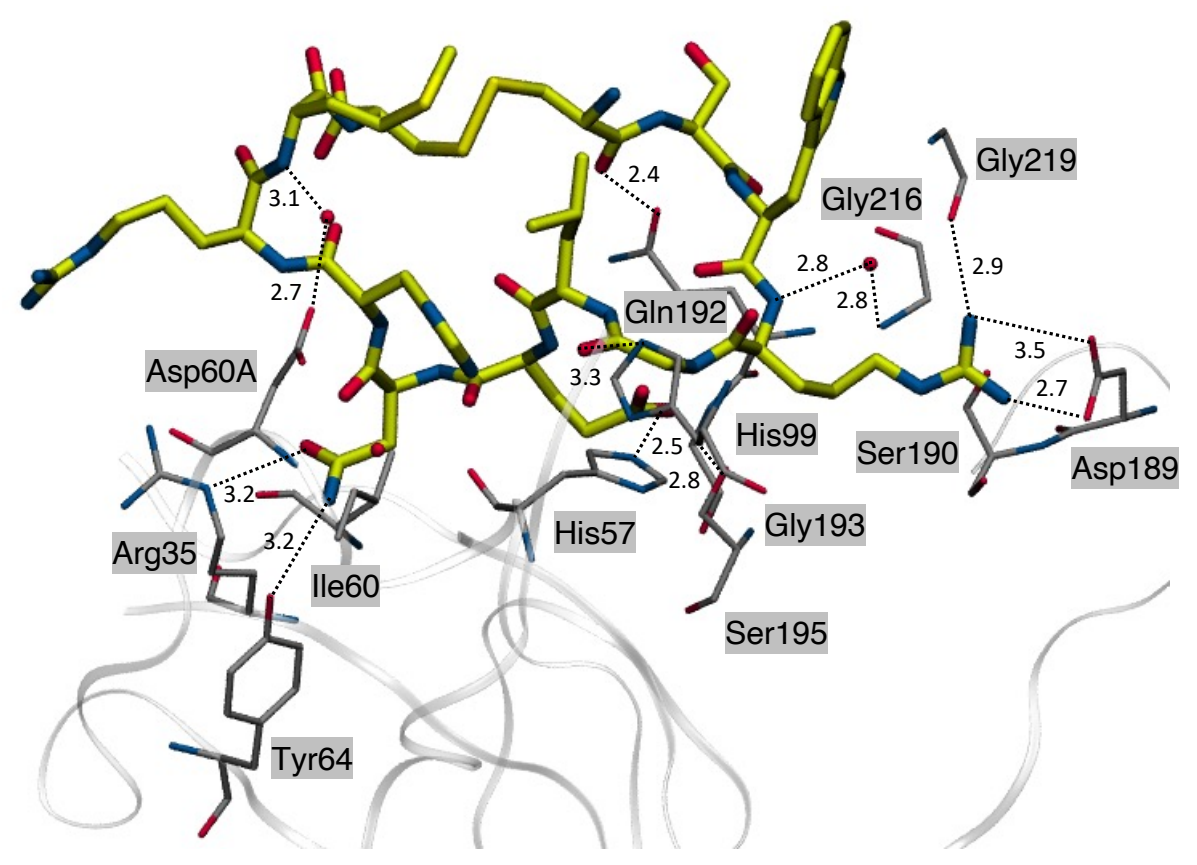

45

Upain-1

$K_{\mathrm{i}} 500 \mathrm{nM}$ 


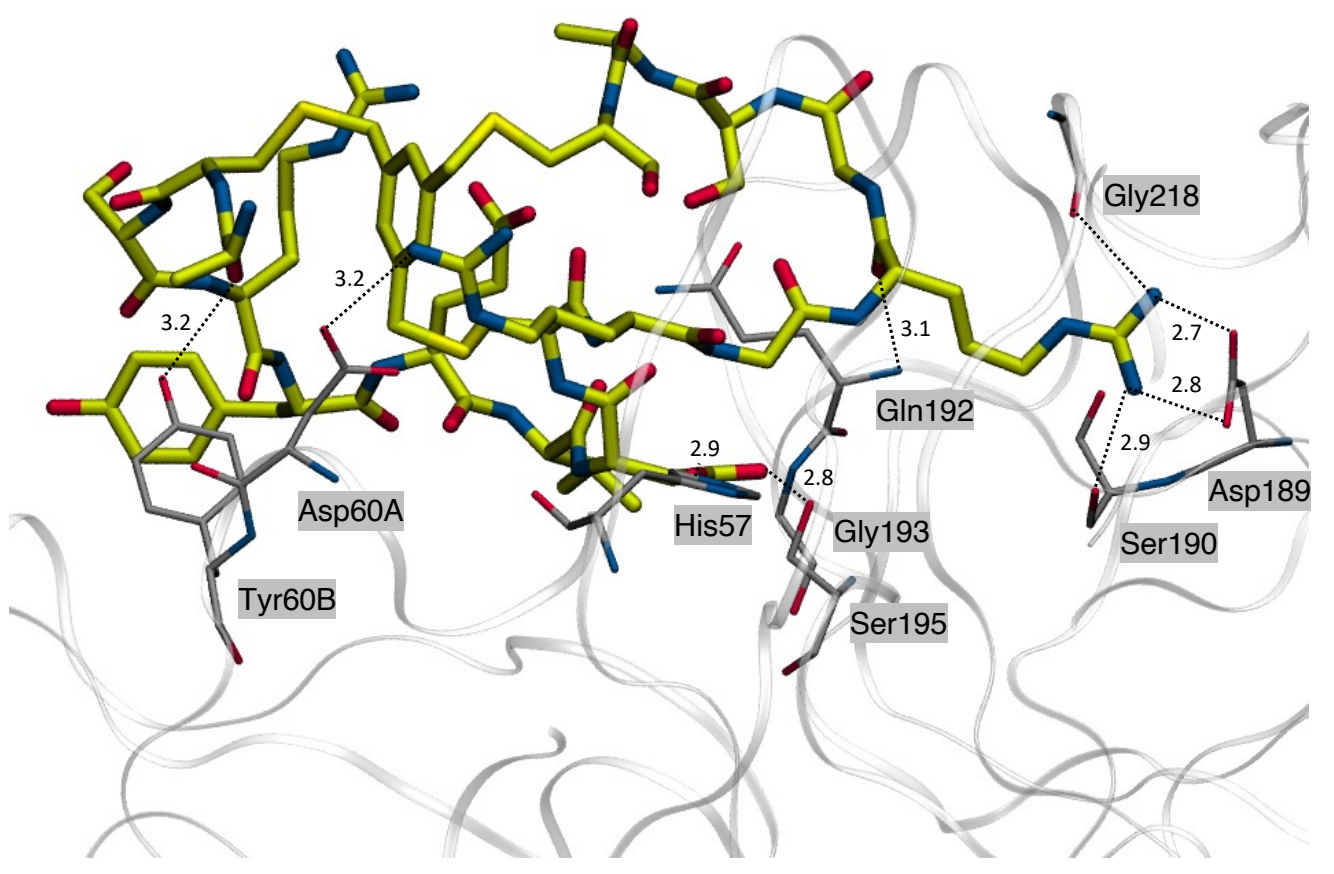

47

$K_{\mathrm{i}} 53 \mathrm{nM}$

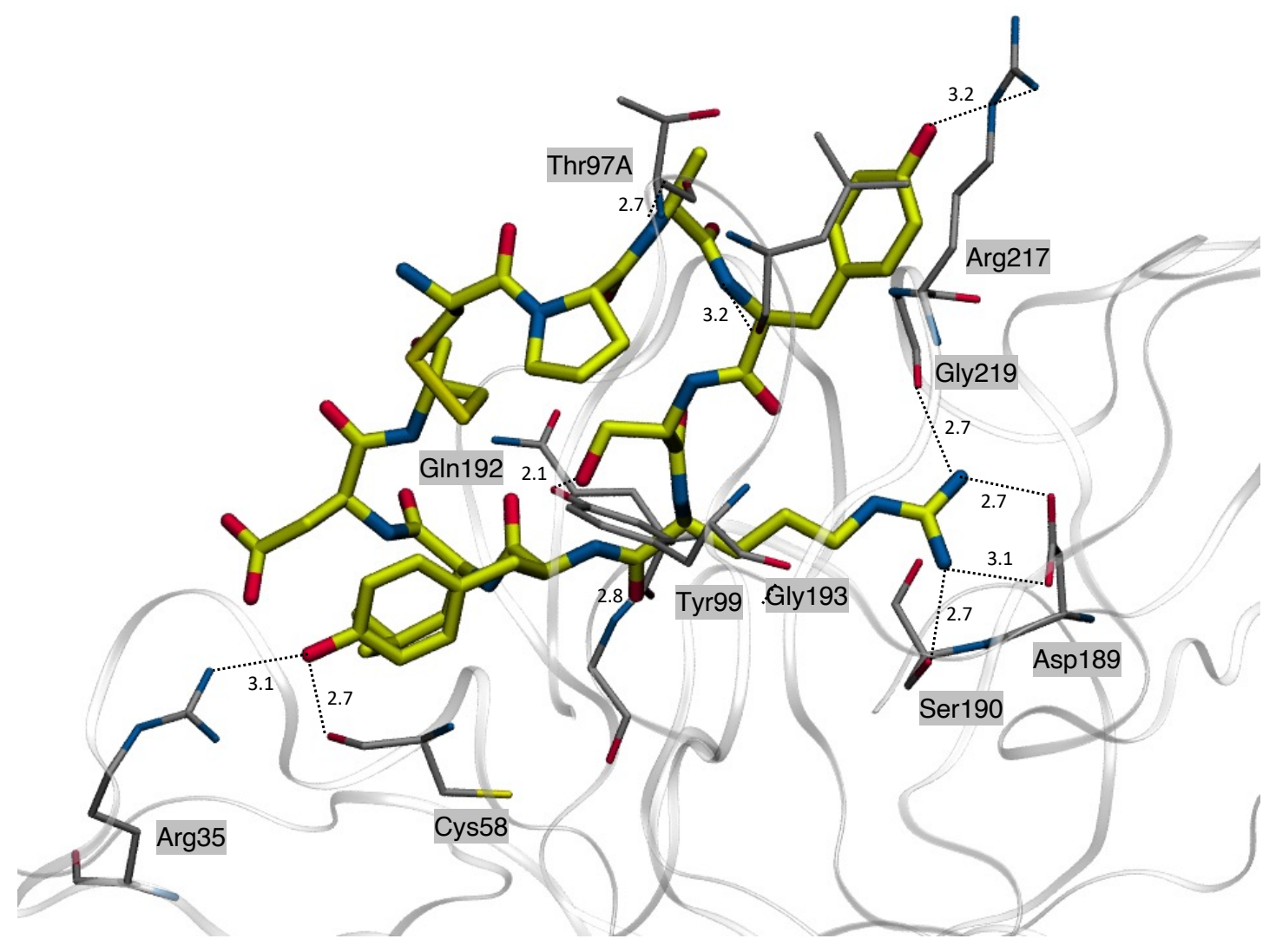

48

Mupain-1

$K_{\mathrm{i}} 500 \mathrm{nM}$ 
Fig. 11 X-ray co-crystal structures of cyclic peptide uPA inhibitors $\mathbf{4 5}, \mathbf{4 7}$ and $\mathbf{4 8}$ showing key interactions. Reported $K_{\mathrm{i}}$ against human uPA for $\mathbf{4 5}$ and $\mathbf{4 7}$ and against the partially murinised human uPA (H99Y) for $\mathbf{4 8}$ are shown.

\section{Species specificity of uPA inhibitors}

Studies have shown that uPA secreted by the tumour stroma plays an important role in cell growth and dissemination in xenograft rodent models (Frandsen et al. 2001; Rømer et al. 1994). Some studies suggested that tumour stromal cells (e.g. endothelial cells, fibroblasts and macrophages) are in fact the predominant uPA expressing tissue (Hildenbrand et al. 2009). Tumour and stromal expression of uPA and/or uPAR at the invasive front of tumours has been demonstrated in human breast xenograft models (Frandsen et al. 2001; Ploug et al. 2001; Rømer et al. 1994) and in patient specimens (Alpízar-Alpízar et al. 2012; Brungs et al. 2017; Illemann et al. 2009; Pyke et al. 1991). Anticancer therapies should therefore target tumour and stromal uPA as they both play an important role in tumour invasion and proliferation (Hofmeister et al. 2008). This creates problems, however, when inhibitors show differences in potency against uPA from human tumour xenografts and uPA secreted by the mouse-derived stromal tissues as it may confound interpretation of on-target efficacy.

Human and mouse uPA are highly homologous, with their protease catalytic domains showing an overall identity of 71\% (Klinghofer et al. 2001). Their active sites contain only four different residues: Asp60, His99, Ser146 and Gln192 in human uPA and Gln60, Tyr99, Glu146 and Lys192 in mouse uPA (Klinghofer et al. 2001) (Fig. 12). Despite this relatively small difference, many small molecule uPA inhibitors show higher potency against human than mouse uPA (Buckley et al. 2018; Klinghofer et al. 2001). 


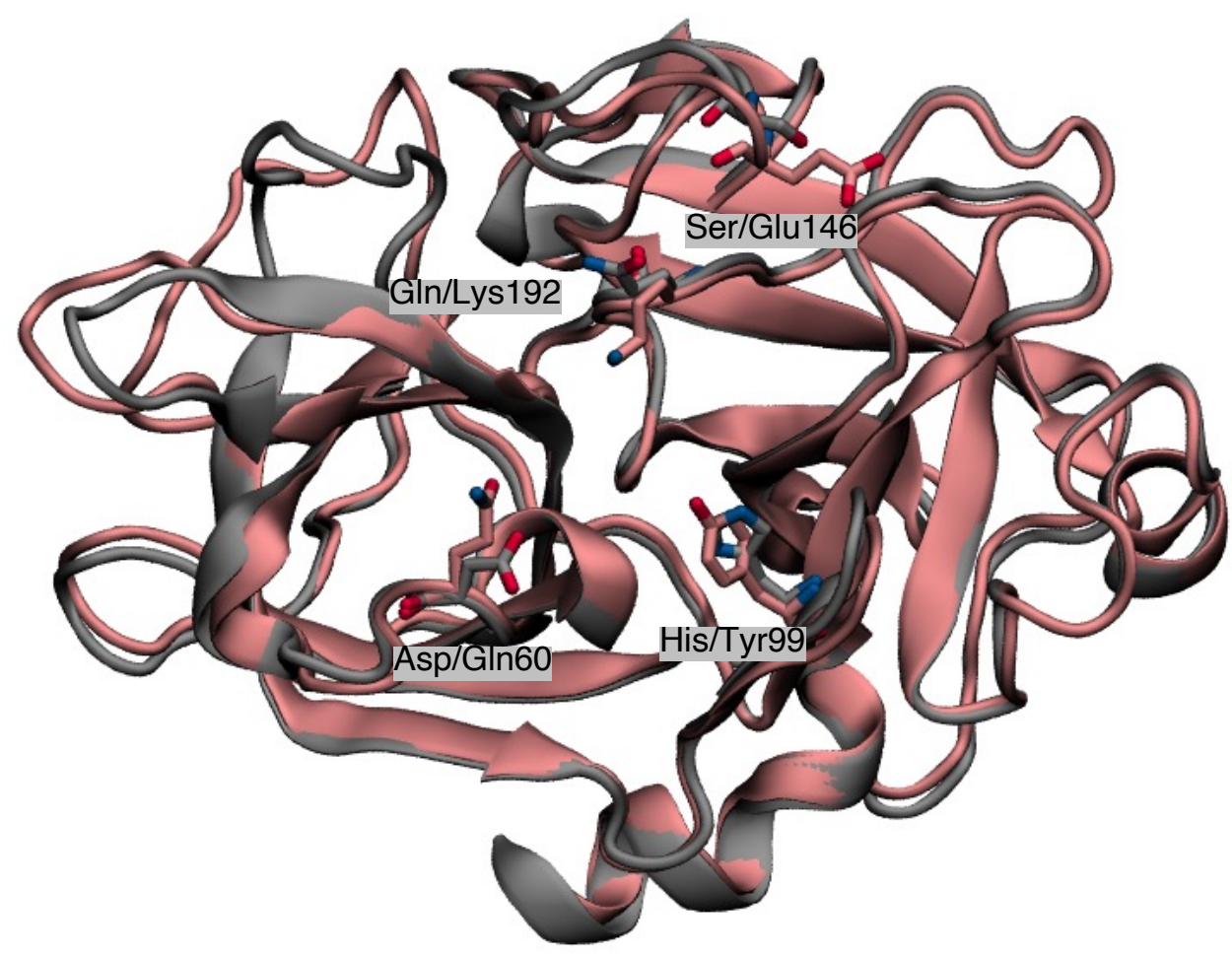

Fig. 12 Superimposed X-ray co-crystal structures of human (PDB 1F5L; $2.1 \AA$ ) (Zeslawska et al. 2000) and mouse (PDB 5LHQ) (Kromann-Hansen et al. 2017) uPA illustrating the four residues $(60,99,146$ and 192) that are close to their binding sites and different between both species.

In 2001, Klinghofer et al. studied the human/mouse species differences for a number of amidine-based uPA inhibitors (Klinghofer et al. 2001). From the X-ray co-crystal structures of B428 5 (human uPA $K_{\mathrm{i}} 100 \mathrm{nM}$ and mouse uPA $K_{\mathrm{i}} 82 \mathrm{nM}$ ), 2-naphthamidine $\mathbf{6}$ (human uPA $K_{\mathrm{i}} 5.9 \mu \mathrm{M}$ and mouse uPA $K_{\mathrm{i}} 6.0 \mu \mathrm{M}$ ) and amiloride 14 (human uPA $K_{\mathrm{i}}$ $2.8 \mu \mathrm{M}$ and mouse uPA $K_{\mathrm{i}} 1.7 \mu \mathrm{M}$ ), they concluded that these inhibitors occupy only the S1 pocket, which has similar residues in both species. Accordingly, these inhibitors didn't show significant species specificity (i.e. human/mouse selectivity ratios 1) (Buckley et al. 2018; Klinghofer et al. 2001). Amiloride 14 and B428 5 bear a halogen substituent that can access part of the S1 $\beta$ pocket and show higher inhibitory potency than 2-naphthamidine 6 (Nienaber et al. 2000b). Thus, the S1 $\beta$ pocket was targeted in SBDD efforts to create more potent uPA inhibitors. Naphthamidine analogues with larger structural extensions displayed higher potency for human over mouse uPA (i.e. increased human/mouse selectivity ratios). Among this series, the most potent analogue against human uPA was the disubstituted naphthamidine 11 (human uPA $K_{\mathrm{i}} 0.64 \mathrm{nM}$ and mouse $\mathrm{uPA} K_{\mathrm{i}} 130 \mathrm{nM}$ ), which showed human/mouse selectivity ratio of 203 (Klinghofer et al. 2001). With groups extending beyond the S1 pocket and achieving potency gains by making interactions with the four residues that differ between human and mouse uPA, this compound showed a pronounced selectivity for human over mouse uPA (Klinghofer et al. 2001). 


\section{Species specificity of HMA and 6-substituted analogues}

While amiloride 14 inhibited human and mouse uPA almost equally (Buckley et al. 2018; Klinghofer et al. 2001), HMA 16, showed higher selectivity for human over mouse uPA (human uPA $K_{\mathrm{i}} 1,356 \mathrm{nM}$, mouse uPA $K_{\mathrm{i}} 9,308$ nM, human/mouse selectivity ratio: 6.9). Selectivity was further increased in HMA analogues obtained by introduction of substituents at its 6-position (e.g. compound 15, human uPA $K_{\mathrm{i}} 53 \mathrm{nM}$, mouse uPA $K_{\mathrm{i}} 1,611 \mathrm{nM}$, human/mouse selectivity ratio: 30.4). With some other derivatives, selectivity for the human enzyme was around 130-fold higher than mouse (Buckley et al. 2018). Such large species differences may complicate development of these inhibitors due to poor inhibition of mouse uPA affecting interpretation of data from human-mouse xenograft tumour models (Schweinitz et al. 2004). Inhibitors effective against both enzymes would offer greater confidence that observed efficacy arises from uPA inhibition, particularly for the determination of minimal effective dosing. Human over mouse species selectivity observed with the 6-substituted HMA analogue 15 was decreased for the corresponding amiloride analogue 49 (human uPA $K_{\mathrm{i}} 204$ nM, mouse uPA $K_{\mathrm{i}} 956 \mathrm{nM}$, human/mouse selectivity ratio: 4.7, Fig. 13). While both inhibitors showed similar interactions with human uPA, the disruption of the water network in presence of mouse uPA was responsible for the observed species selectivity. In 15, the 5-N,N-hexamethylene ring caused unfavourable steric expulsion of a water molecule in presence of mouse uPA (residue 99 is Tyr), while this water molecule was maintained in presence of human uPA (residue 99 is His). In contrast amiloride analogue 49 with its smaller $5-\mathrm{NH}_{2}$ group maintained similar water networks when bound to both human and mouse uPA and didn't display pronounced species selectivity (El Salamouni et al. 2021). 
<smiles>CCc1cnc[nH]1</smiles>

15 bound to human UPA

$K_{\mathrm{i}}=53 \mathrm{nM}$

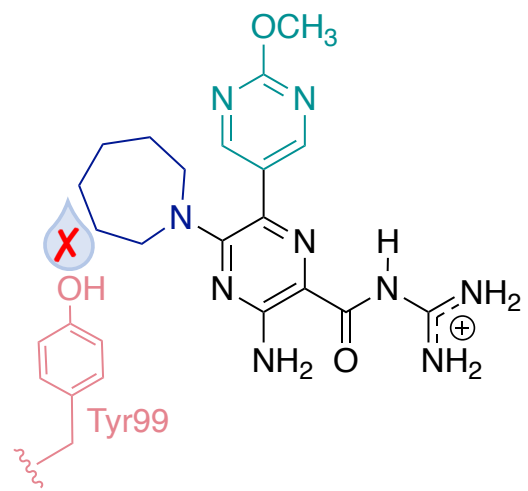

15 bound to mouse uPA

$$
K_{\mathrm{i}}=1,611 \mathrm{nM}
$$

Human/Mouse selectivity factor $=30.4$<smiles>CCc1cnc[nH]1</smiles>

49 bound to human UPA

$K_{\mathrm{i}}=204 \mathrm{nM}$<smiles>CCCc1ccc(OC2=CC=C2)cc1</smiles>

49 bound to mouse UPA

$$
K_{\mathrm{i}}=956 \mathrm{nM}
$$

Human/Mouse selectivity factor $=4.7$

Fig. 13 Differences in water networks and changes at residue 99 explain the human and mouse species differences for inhibitors 15 and 49. Reported $K_{\mathrm{i}}$ against human (top) and mouse (bottom) uPA are shown.

\section{Conclusion}

uPA is an important anti-metastasis drug target that has attracted ongoing efforts to develop potent and selective inhibitors with good drug properties. While the earlier highly basic amidine and guanidine-based inhibitors showed poor oral bioavailability, potent less basic inhibitors of uPA have been developed. 6-Substituted amiloride and HMA analogues that show nanomolar uPA potency and high selectivity over other TLSPs were recently described. The availability of Xray co-crystal structures of these inhibitors in complex with uPA has enabled an intricate understanding of the key binding interactions. Most inhibitors maintain the critical salt bridge with Asp189 in the S1 pocket. Interactions of some inhibitors with Ser190 confer selectivity for uPA over closely related TLSPs that instead have Ala190. Many uPA inhibitors form 
hydrogen bonds with Gly219 located at the periphery of the S1 $\beta$ subsite, with those extending deeper showing high affinity. While aiming to develop inhibitors that can target both human and mouse uPA to be used reliably in cancer models, some analogues show human/mouse species selectivity, which may complicate the interpretation of efficacy signals from xenografted mouse models of cancer. Recent computational findings supported by experimental data suggested that 6-substituted amiloride analogues are less likely to show human/mouse species selectivity and that residue 99 is a key contributor to this observed selectivity.

\section{Conflict of interest}

The authors declare no conflicts of interest.

\section{Funding}

This work was funded by an Australian National Health and Medical Research Council (NHMRC) Project Grant (APP1100432) awarded to M.K. and M.R., a UOW SMAH Small Research Grant (H.Y.) and a UOW RevITAlising Research Grant (N.S.E. and H.Y.). B.J.B. gratefully acknowledges salary support from the Illawarra Cancer Carers.

\section{References}

Al-Sha'er MA, Khanfar, MA \& Taha, MO (2014) Discovery of novel urokinase plasminogen activator (uPA) inhibitors using ligand-based modeling and virtual screening followed by in vitro analysis. J Mol Model 20(1):20802084. https://doi.org/10.1007/s00894-014-2080-4

Alipranti FX, Masih, M, Torres-Paris, C \& Komives, EA (2020) S195A is a catalytically inactive mutant of the protease domain of the urokinase-type plasminogen activator (uPA). Biophys J 118(3, Supplement 1):50a. https://doi.org/10.1016/j.bpj.2019.11.455

Alpízar-Alpízar W, Christensen, IJ, Santoni-Rugiu, E, Skarstein, A, Ovrebo, K, Illemann, M \& Laerum, OD (2012) Urokinase plasminogen activator receptor on invasive cancer cells: a prognostic factor in distal gastric adenocarcinoma. Int J Cancer 131(4):E329-E336. https://doi.org/10.1002/ijc.26417

Andersen LM, Wind, T, Hansen, HD \& Andreasen, PA (2008) A cyclic peptidylic inhibitor of murine urokinase-type plasminogen activator: changing species specificity by substitution of a single residue. Biochem J 412(3):447457. https://doi.org/10.1042/BJ20071646

Andreasen PA, Egelund, R \& Petersen, HH (2000) The plasminogen activation system in tumor growth, invasion, and metastasis. Cell Mol Life Sci 57(1):25-40. https://doi.org/10.1007/s000180050497

Andreasen PA, Kjoller, L, Christensen, L \& Duffy, MJ (1997) The urokinase-type plasminogen activator system in cancer metastasis: a review. Int J cancer 72(1):1-22. https://doi.org/10.1002/(SICI)10970215(19970703)72:1<1::AID-IJC1>3.0.CO;2-Z

Angelini A, Cendron, L, Chen, S, Touati, J, Winter, G, Zanotti, G \& Heinis, C (2012) Bicyclic peptide inhibitor reveals large contact interface with a protease target. ACS Chem Biol 7(5):817-821. https://doi.org/10.1021/cb200478t

Bansal V \& Roychoudhury, PK (2006) Production and purification of urokinase: a comprehensive review. Protein Expr Purif 45(1):1-14. https://doi.org/10.1016/j.pep.2005.06.009

Banys-Paluchowski M, Witzel, I, Aktas, B, Fasching, PA, Hartkopf, A, Janni, W, Kasimir-Bauer, S, Pantel, K, Schön, G \& Rack, B (2019) The prognostic relevance of urokinase-type plasminogen activator (uPA) in the blood of patients with metastatic breast cancer. Sci Rep 9(1):1-10. https://doi.org/10.1055/s-0038-1675453

Barber CG, Dickinson, RP \& Fish, PV (2004) Selective urokinase-type plasminogen activator (uPA) inhibitors. Part 3: 1-Isoquinolinylguanidines. Bioorg Med Chem Lett 14(12):3227-3230. https://doi.org/10.1016/j.bmcl.2004.03.094

Blasi F (1988) Surface receptors for urokinase plasminogen activator. Fibrinolysis 2(2):73-84. https://doi.org/10.1016/0268-9499(88)90370-0 
Bouchet C, Spyratos, F, Martin, PM, Hacène, K, Gentile, A \& Oglobine, J (1994) Prognostic value of urokinase-type plasminogen activator (UPA) and plasminogen activator inhibitors PAI-1 and PAI-2 in breast carcinomas. Br J Cancer 69(2):398-405. https://doi.org/10.1038/bjc.1994.74

Bridges AJ, Lee, A, Schwartz, CE, Towle, MJ \& Littlefield, BA (1993) The synthesis of three 4substitutedbenzo[b]thiophene-2-carboxamidines as potent and selective inhibitors of urokinase. Biorg Med Chem 1(6):403-410. https://doi.org/10.1016/S0968-0896(00)82150-1

Bruncko M, Mcclellan, WJ, Wendt, MD, Sauer, DR, Geyer, A, Dalton, CR, Kaminski, MA, Weitzberg, M, Gong, J \& Dellaria, JF (2005) Naphthamidine urokinase plasminogen activator inhibitors with improved pharmacokinetic properties. Biorg Med Chem Lett 15(1):93-98. https://doi.org/10.1016/j.bmcl.2004.10.026

Brungs D, Chen, J, Aghmesheh, M, Vine, KL, Becker, TM, Carolan, MG \& Ranson, M (2017) The urokinase plasminogen activation system in gastroesophageal cancer: a systematic review and meta-analysis. Oncotarget 8(14):23099-23109. https://doi.org/10.18632/oncotarget.15485

Buckley BJ, Aboelela, A, Majed, H, Bujaroski, RS, White, KL, Powell, AK, Wang, W, Katneni, K, Saunders, J \& Shackleford, DM (2021a) Systematic evaluation of structure-property relationships and pharmacokinetics in 6(hetero) aryl-substituted matched pair analogs of amiloride and 5-(N, N-hexamethylene)amiloride. Biorg Med Chem 37:116116. https://doi.org/10.1016/j.bmc.2021.116116

Buckley BJ, Aboelela, A, Minaei, E, Jiang, LX, Xu, Z, Ali, U, Fildes, K, Cheung, C-Y, Cook, SM \& Johnson, DC (2018) 6-Substituted hexamethylene amiloride (HMA) derivatives as potent and selective inhibitors of the human urokinase plasminogen activator for use in cancer. J Med Chem 61(18):8299-8320. https://doi.org/10.1021/acs.jmedchem.8b00838

Buckley BJ, Ali, U, Kelso, MJ \& Ranson, M (2019) The urokinase plasminogen activation system in rheumatoid arthritis: pathophysiological roles and prospective therapeutic targets. Curr Drug Targets 20(9):970-981. https://doi.org/10.2174/1389450120666181204164140

Buckley BJ, Kumar, A, Aboelela, A, Bujaroski, RS, Li, X, Majed, H, Fliegel, L, Ranson, M \& Kelso, MJ (2021b) Screening of 5-and 6-substituted amiloride libraries identifies dual-uPA/NHE1 active and single targetselective inhibitors. Int J Mol Sci 22(6):2999. https://doi.org/10.3390/ijms22062999

Bum-Erdene K, Liu, D, Xu, D, Ghozayel, MK \& Meroueh, SO (2020) Design and synthesis of fragment derivatives with a unique inhibition mechanism of the uPAR $\cdot$ uPA interaction. ACS Med Chem Lett 12(1):60-66. https://doi.org/10.1021/acsmedchemlett.0c00422

Cho WC, Jour, G \& Aung, PP (2019) Role of angiogenesis in melanoma progression: Update on key angiogenic mechanisms and other associated components. Semin Cancer Biol 59:175-186. https://doi.org/10.1016/j.semcancer.2019.06.015

Cragoe EJ, Woltersdorf, OW, Bicking, JB, Kwong, SF \& Jones, JH (1967) Pyrazine diuretics. II. N-amidino-3-amino-5substituted 6-halopyrazinecarboxamides. J Med Chem 10(1):66-75. https://doi.org/10.1021/jm00313a014

Croucher DR, Saunders, DN, Lobov, S \& Ranson, M (2008) Revisiting the biological roles of PAI2 (SERPINB2) in cancer. Nat Rev Cancer 8(7):535. https://doi.org/10.1038/nrc2400

Denis JDS, Hall, RJ, Murray, CW, Heightman, TD \& Rees, DC (2021) Fragment-based drug discovery: Opportunities for organic synthesis. RSC Med Chem 12(3):321-329. https://doi.org/10.1039/D0MD00375A

Di Cera E (2009) Serine proteases. IUBMB Life 61(5):510-515. https://doi.org/10.1002/iub.186

Didiasova M, Wujak, L, Wygrecka, M \& Zakrzewicz, D (2014) From plasminogen to plasmin: Role of plasminogen receptors in human cancer. Int J Mol Sci 15(11):21229-21252. https://doi.org/10.3390/ijms151121229

Duffy MJ \& Duggan, C (2004) The urokinase plasminogen activator system: A rich source of tumour markers for the individualised management of patients with cancer. Clin Biochem 37(7):541-548. https://doi.org/10.1016/j.clinbiochem.2004.05.013

Duffy MJ, O'siorain, L, O'grady, P, Devaney, D, Fennelly, JJ \& Lijnen, HJ (1988) Urokinase-plasminogen activator, a marker for aggressive breast carcinomas. Preliminary report. Cancer 62(3):531-533. https://doi.org/10.1002/1097-0142(19880801)62:3<531::AID-CNCR2820620315>3.0.CO;2-B

El Salamouni N, Buckley, B, Jiang, L, Huang, M, Ranson, M, Kelso, M \& Yu, H (2021) Disruption of water networks is the cause of human/mouse species selectivity in urokinase plasminogen activator (uPA) inhibitors derived from hexamethylene amiloride (HMA). Chemrxiv. Preprint. https://doi.org/10.33774/chemrxiv-2021-c6lrq

Fathi R, Levitt, M, Plasse, T \& Abramson, D (2019) Use of wx-uk1 and its prodrug, wx-671, for the treatment of noncancerous medical conditions. US 2019/0022088A1 RedHill Biopharma Ltd. (Tel-Aviv, IL). https://patents.google.com/patent/US20190022088A1/en

Fish PV, Barber, CG, Brown, DG, Butt, R, Collis, MG, Dickinson, RP, Henry, BT, Horne, VA, Huggins, JP, King, E, O'gara, M, Mccleverty, D, Mcintosh, F, Phillips, C \& Webster, R (2007) Selective urokinase-type plasminogen activator inhibitors. 4. 1-(7-sulfonamidoisoquinolinyl)guanidines. J Med Chem 50(10):2341-2351. https://doi.org/10.1021/jm061066t

Foekens JA, Peters, HA, Look, MP, Portengen, H, Schmitt, M, Kramer, MD, Brünner, N, Jänicke, F, Meijer-Van Gelder, ME, Henzen-Logmans, SC, Van Putten, WL \& Klijn, JG (2000) The urokinase system of plasminogen activation and prognosis in 2780 breast cancer patients. Cancer Res 60(3):636-643.

https://cancerres.aacrjournals.org/content/60/3/636.short

Frandsen TL, Holst-Hansen, C, Nielsen, BS, Christensen, IJ, Nyengaard, JR, Carmeliet, P \& Brünner, N (2001) Direct evidence of the importance of stromal urokinase plasminogen activator (uPA) in the growth of an experimental 
human breast cancer using a combined uPA gene-disrupted and immunodeficient xenograft model. Cancer Res 61(2):532-537. https://cancerres.aacrjournals.org/content/61/2/532.short

Frederickson M, Callaghan, O, Chessari, G, Congreve, M, Cowan, SR, Matthews, JE, Mcmenamin, R, Smith, D-M, Vinković, M \& Wallis, NG (2008) Fragment-based discovery of mexiletine derivatives as orally bioavailable inhibitors of urokinase-type plasminogen activator. J Med Chem 51(2):183-186. https://doi.org/10.1021/jm701359z

Giordanetto F, Jin, C, Willmore, L, Feher, M \& Shaw, DE (2019) Fragment hits: What do they look like and how do they bind? J Med Chem 62(7):3381-3394. https://doi.org/10.1021/acs.jmedchem.8b01855

Gladysz R, Adriaenssens, Y, De Winter, H, Joossens, J, Lambeir, A-M, Augustyns, K \& Van Der Veken, P (2015) Discovery and SAR of novel and selective inhibitors of urokinase plasminogen activator (uPA) with an imidazo[1,2-a]pyridine scaffold. J Med Chem 58(23):9238-9257.

https://doi.org/10.1021/acs.jmedchem.5b01171

Goldstein LJ (2008) Experience in phase I trials and an upcoming phase II study with uPA inhibitors in metastatic breast cancer. Breast Care 3(Suppl 2):25. https://doi.org/10.1159/000151733

Gong L, Proulle, V, Fang, C, Hong, Z, Lin, Z, Liu, M, Xue, G, Yuan, C, Lin, L \& Furie, B (2016) A specific plasminogen activator inhibitor-1 antagonist derived from inactivated urokinase. J Cell Mol Med 20(10):18511860. https://doi.org/10.1111/jcmm.12875

Hajduk PJ, Boyd, S, Nettesheim, D, Nienaber, V, Severin, J, Smith, R, Davidson, D, Rockway, T \& Fesik, SW (2000) Identification of novel inhibitors of urokinase via NMR-based screening. J Med Chem 43(21):3862-3866. https://doi.org/10.1021/jm0002228

Hall SW, Humphries, JE \& Gonias, SL (1991) Inhibition of cell surface receptor-bound plasmin by alpha 2-antiplasmin and alpha 2-macroglobulin. J Biol Chem 266(19):12329-12336. https://doi.org/10.1016/S00219258(18)98900-3

Hansen M, Wind, T, Blouse, GE, Christensen, A, Petersen, HH, Kjelgaard, S, Mathiasen, L, Holtet, TL \& Andreasen, PA (2005) A urokinase-type plasminogen activator-inhibiting cyclic peptide with an unusual P2 residue and an extended protease binding surface demonstrates new modalities for enzyme inhibition. J Biol Chem 280(46):38424-38437. https://doi.org/10.1074/jbc.M505933200

Harbeck N, Kates, RE, Look, MP, Meijer-Van Gelder, ME, Klijn, JG, Krüger, A, Kiechle, M, Jänicke, F, Schmitt, M \& Foekens, JA (2002) Enhanced benefit from adjuvant chemotherapy in breast cancer patients classified highrisk according to urokinase-type plasminogen activator (uPA) and plasminogen activator inhibitor type $1(\mathrm{n}=$ 3424). Cancer Res 62(16):4617-4622. https://cancerres.aacrjournals.org/content/62/16/4617.article-info

Hasui Y \& Osada, Y (1997) Urokinase-type plasminogen activator and its receptor in bladder cancer. J Natl Cancer Inst 89(10):678-679. https://doi.org/10.1093/jnci/89.10.678

Hedstrom L (2002) Serine protease mechanism and specificity. Chem Rev 102(12):4501-4524. https://doi.org/10.1021/cr000033x

Henneke I, Greschus, S, Savai, R, Korfei, M, Markart, P, Mahavadi, P, Schermuly, RT, Wygrecka, M, Stürzebecher, J, Seeger, W, Günther, A \& Ruppert, C (2010) Inhibition of urokinase activity reduces primary tumor growth and metastasis formation in a murine lung carcinoma model. Am J Respir Crit Care Med 181(6):611-619. https://doi.org/10.1164/rccm.200903-03420C

Hildenbrand R, Schaaf, A, Dorn-Beineke, A, Allgayer, H, Sütterlin, M, Marx, A \& Stroebel, P (2009) Tumor stroma is the predominant UPA, uPAR, PAI-1-expressing tissue in human breast cancer: prognostic impact. Histol Histopathol 24(7):869-877. https://doi.org/10.14670/HH-24.869

Hirsh AJ, Molino, BF, Zhang, J, Astakhova, N, Geiss, WB, Sargent, BJ, Swenson, BD, Usyatinsky, A, Wyle, MJ, Boucher, RC, Smith, RT, Zamurs, A \& Johnson, MR (2006) Design, synthesis, and structure-activity relationships of novel 2-substituted pyrazinoylguanidine epithelial sodium channel blockers: drugs for cystic fibrosis and chronic bronchitis. J Med Chem 49(14):4098-4115. https://doi.org/10.1021/jm051134w

Hofmeister V, Schrama, D \& Becker, JC (2008) Anti-cancer therapies targeting the tumor stroma. Cancer Immunol Immunother 57(1):1-17. https://doi.org/10.1007/s00262-007-0365-5

Hunkapiller MW, Forgac, MD \& Richards, JH (1976) Mechanism of action of serine proteases: tetrahedral intermediate and concerted proton transfer. Biochem 15(25):5581-5588. https://doi.org/10.1021/bi00670a024

Illemann M, Bird, N, Majeed, A, Lærum, OD, Lund, LR, Danø, K \& Nielsen, BS (2009) Two distinct expression patterns of urokinase, urokinase receptor and plasminogen activator inhibitor-1 in colon cancer liver metastases. Int J Cancer 124(8):1860-1870. https://doi.org/10.1002/ijc.24166

Islam I, Yuan, S, West, CW, Adler, M, Bothe, U, Bryant, J, Chang, Z, Chu, K, Emayan, K, Gualtieri, G, Ho, E, Light, D, Mallari, C, Morser, J, Phillips, G, Schaefer, C, Sukovich, D, Whitlow, M, Chen, D \& Buckman, BO (2018) Discovery of selective urokinase plasminogen activator (uPA) inhibitors as a potential treatment for multiple sclerosis. Biorg Med Chem Lett 28(20):3372-3375. https://doi.org/10.1016/j.bmcl.2018.09.001

Iwata T, Kimura, S, Abufaraj, M, Janisch, F, Parizi, MK, Haitel, A, Rink, M, Rouprêt, M, Fajkovic, H, Seebacher, V, Nyirady, P, Karakiewicz, PI, Enikeev, D, Rapoport, LM, Nasu, Y \& Shariat, SF (2019) Prognostic role of the urokinase plasminogen activator (uPA) system in patients with nonmuscle invasive bladder cancer. Urol Oncol: Seminars and Original Investigations 37(10):774-783. https://doi.org/10.1016/j.urolonc.2019.05.019 
Jiang L, Zhang, X, Zhou, Y, Chen, Y, Luo, Z, Li, J, Yuan, C \& Huang, M (2018) Halogen bonding for the design of inhibitors by targeting the S1 pocket of serine proteases. RSC advances 8(49):28189-28197. https://doi.org/10.1039/C8RA03145B

Kaneko T, Konno, H, Baba, M, Tanaka, T \& Nakamura, S (2003) Urokinase-type plasminogen activator expression correlates with tumor angiogenesis and poor outcome in gastric cancer. Cancer Sci 94(1):43-49. https://doi.org/10.1111/j.1349-7006.2003.tb01350.x

Karthikeyan C, Moorthy, NSHN \& Trivedi, P (2009) QSAR study of substituted 2-pyridinyl guanidines as selective urokinase-type plasminogen activator (uPA) inhibitors. J Enzyme Inhib Med Chem 24(1):6-13. https://doi.org/10.1080/14756360701810355

Kasai S, Arimura, H, Nishida, M \& Suyama, T (1985) Primary structure of single-chain pro-urokinase. J Biol Chem 260(22):12382-12389. https://doi.org/10.1016/S0021-9258(17)39036-1

Katz BA, Elrod, K, Luong, C, Rice, MJ, Mackman, RL, Sprengeler, PA, Spencer, J, Hataye, J, Janc, J \& Link, J (2001a) A novel serine protease inhibition motif involving a multi-centered short hydrogen bonding network at the active site. J Mol Biol 307(5):1451-1486. https://doi.org/10.1006/jmbi.2001.4516

Katz BA, Mackman, R, Luong, C, Radika, K, Martelli, A, Sprengeler, PA, Wang, J, Chan, H \& Wong, L (2000) Structural basis for selectivity of a small molecule, S1-binding, submicromolar inhibitor of urokinase-type plasminogen activator. Chem Biol 7(4):299-312. https://doi.org/10.1016/S1074-5521(00)00104-6

Katz BA, Sprengeler, PA, Luong, C, Verner, E, Elrod, K, Kirtley, M, Janc, J, Spencer, JR, Breitenbucher, JG \& Hui, H (2001b) Engineering inhibitors highly selective for the S1 sites of Ser 190 trypsin-like serine protease drug targets. Chem Biol 8(11):1107-1121. https://doi.org/10.1016/S1074-5521(01)00084-9

Ke S-H, Coombs, GS, Tachias, K, Corey, DR \& Madison, EL (1997) Optimal subsite occupancy and design of a selective inhibitor of urokinase. J Biol Chem 272(33):20456-20462. https://doi.org/10.1074/jbc.272.33.20456

Kimura S, D'andrea, D, Iwata, T, Foerster, B, Janisch, F, Parizi, MK, Moschini, M, Briganti, A, Babjuk, M, Chlosta, P, Karakiewicz, PI, Enikeev, D, Rapoport, LM, Seebacher, V, Egawa, S, Abufaraj, M \& Shariat, SF (2020) Expression of urokinase-type plasminogen activator system in non-metastatic prostate cancer. World J Urol 38(10):2501-2511. https://doi.org/10.1007/s00345-019-03038-5

Klinghofer V, Stewart, K, Mcgonigal, T, Smith, R, Sarthy, A, Nienaber, V, Butler, C, Dorwin, S, Richardson, P, Weitzberg, M, Wendt, M, Rockway, T, Zhao, X, Hulkower, KI \& Giranda, VL (2001) Species specificity of amidine-based urokinase inhibitors. Biochem 40(31):9125-9131. https://doi.org/10.1021/bi010186u

Kromann-Hansen T, Louise Lange, E, Peter Sørensen, H, Hassanzadeh-Ghassabeh, G, Huang, M, Jensen, JK, Muyldermans, S, Declerck, PJ, Komives, EA \& Andreasen, PA (2017) Discovery of a novel conformational equilibrium in urokinase-type plasminogen activator. Sci Rep 7(1):3385. 10.1038/s41598-017-03457-7

Kubala MH \& Declerck, YA (2019) The plasminogen activator inhibitor-1 paradox in cancer: a mechanistic understanding. Cancer Metastasis Rev 38(3):483-492. https://doi.org/10.1007/s10555-019-09806-4

Kugaevskaya EV, Gureeva, TA, Timoshenko, OS \& Solovyeva, NI (2018) The urokinase-type plasminogen activator system and its role in tumor progression. Biomed Khim 64(6):472-486. https://doi.org/10.18097/pbmc20186406472

Künzel S, Schweinitz, A, Reißmann, S, Stürzebecher, J \& Steinmetzer, T (2002) 4-amidinobenzylamine-based inhibitors of urokinase. Bioorg Med Chem Lett 12(4):645-648. https://doi.org/10.1016/S0960-894X(01)00815$\underline{0}$

Law RHP , Wu, G, Leung, EWW, Hidaka, K, Quek, AJ, Caradoc-Davies, TT, Jeevarajah, D, Conroy, PJ, Kirby, NM, Norton, RS, Tsuda, Y \& Whisstock, JC (2017) X-ray crystal structure of plasmin with tranexamic acid-derived active site inhibitors. Blood Advances 1(12):766-771. https://doi.org/10.1182/bloodadvances.2016004150

Lee M, Fridman, R \& Mobashery, S (2004) Extracellular proteases as targets for treatment of cancer metastases. Chem Soc Rev 33(7):401-409. https://doi.org/10.1039/B209224G

Lenich C, Pannell, R, Henkin, J \& Gurewich, V (1992) The influence of glycosylation on the catalytic and fibrinolytic properties of pro-urokinase. Thromb Haemost 68(11):539-544. https://doi.org/10.1055/s-0038-1646314

Li CY, De Veer, SJ, Law, RH, Whisstock, JC, Craik, DJ \& Swedberg, JE (2019) Characterising the subsite specificity of urokinase-type plasminogen activator and tissue-type plasminogen activator using a sequence-defined peptide aldehyde library. ChemBioChem 20(1):46-50. https://doi.org/10.1002/cbic.201800395

Liu Z, Kromann-Hansen, T, Lund, IK, Hosseini, M, Jensen, KJ, Høyer-Hansen, G, Andreasen, PA \& Sørensen, HP (2012) Interconversion of active and inactive conformations of urokinase-type plasminogen activator. Biochemistry 51(39):7804-7811. https://doi.org/10.1021/bi3005957

Mackman RL, Hui, HC, Breitenbucher, JG, Katz, BA, Luong, C, Martelli, A, Mcgee, D, Radika, K, Sendzik, M, Spencer, JR, Sprengeler, PA, Tario, J, Verner, E \& Wang, J (2002) 2-(2-Hydroxy-3-alkoxyphenyl)-1Hbenzimidazole-5-carboxamidine derivatives as potent and selective urokinase-type plasminogen activator inhibitors. Bioorg Med Chem Lett 12(15):2019-2022. http://dx.doi.org/10.1016/S0960-894X(02)00311-6

Mackman RL, Katz, BA, Breitenbucher, JG, Hui, HC, Verner, E, Luong, C, Liu, L \& Sprengeler, PA (2001) Exploiting subsite S1 of trypsin-like serine proteases for selectivity: potent and selective inhibitors of urokinase-type plasminogen activator. J Med Chem 44(23):3856-3871. https://doi.org/10.1021/jm010244+

Magill C, Katz, BA \& Mackman, RL (1999) Emerging therapeutic targets in oncology: urokinase-type plasminogen activator system. Emerg Ther Targets 3(1):109-133. https://doi.org/10.1517/14728222.3.1.109 
Mahmood N, Mihalcioiu, C \& Rabbani, SA (2018) Multifaceted role of the urokinase-type plasminogen activator (uPA) and Its receptor (uPAR): Diagnostic, prognostic, and therapeutic applications. Front Oncol 8(24). https://doi.org/10.3389/fonc.2018.00024

Masih M, Alipranti, FX, Torres-Paris, C \& Komives, EA (2020) Dynamic consequences of Inactivating the catalytic serine 195 to methionine in the human urokinase-type plasminogen activator (uPA). Biophys J 118(3):53a-54a. https://doi.org/10.1016/j.bpj.2019.11.473

Matthews H, Ranson, M \& Kelso, MJ (2011a) Anti-tumour/metastasis effects of the potassium-sparing diuretic amiloride: An orally active anti-cancer drug waiting for its call-of-duty? Int J Cancer 129(9):2051-2061. https://doi.org/10.1002/ijc.26156

Matthews H, Ranson, M, Tyndall, JDA \& Kelso, MJ (2011b) Synthesis and preliminary evaluation of amiloride analogs as inhibitors of the urokinase-type plasminogen activator (uPA). Bioorg Med Chem Lett 21(22):6760-6766. https://doi.org/10.1016/j.bmcl.2011.09.044

Mccormack PL (2012) Tranexamic acid: a review of its use in the treatment of hyperfibrinolysis. Drugs 72(5):585-617. https://doi.org/10.2165/11209070-000000000-00000

Ngo JCK, Jiang, L, Lin, Z, Yuan, C, Chen, Z, Zhang, X, Yu, H, Wang, J, Lin, L \& Huang, M (2011) Structural basis for therapeutic intervention of uPA/uPAR system. Curr Drug Targets 12(12):1729-1743. https://doi.org/10.2174/138945011797635911

Nienaber V, Wang, J, Davidson, D \& Henkin, J (2000a) Re-engineering of human urokinase provides a system for structure-based drug design at high resolution and reveals a novel structural subsite. J Biol Chem 275(10):7239-7248. https://doi.org/10.1074/jbc.275.10.7239

Nienaber VL, Davidson, D, Edalji, R, Giranda, VL, Klinghofer, V, Henkin, J, Magdalinos, P, Mantei, R, Merrick, S \& Severin, JM (2000b) Structure-directed discovery of potent non-peptidic inhibitors of human urokinase that access a novel binding subsite. Struct 8(5):553-563. https://doi.org/10.1016/S0969-2126(00)00136-2

Oldenburg E, Schar, CR, Lange, E, Plasse, TF, Abramson, DT, Fathi, R, Towler, EM, Levitt, M \& Jensen, JK (2018) Abstract 4200: New potential therapeutic applications of WX-UK1, as a specific and potent inhibitor of human trypsin-like proteases. Cancer Res 78(13 Supplement):4200. https://doi.org/10.1158/1538-7445.AM2018-4200

Özdirik B, Stueven, A, Knorr, J, Geisler, L, Mohr, R, Demir, M, Hellberg, T, Loosen, SH, Benz, F \& Wiedenmann, B (2020) Soluble urokinase plasminogen activator receptor (suPAR) concentrations are elevated in patients with neuroendocrine malignancies. J Clin Med 9(6):1647. https://doi.org/10.3390/jcm9061647

Pajouhesh H \& Lenz, GR (2005) Medicinal chemical properties of successful central nervous system drugs. NeuroRx 2(4):541-553. https://doi.org/10.1602/neurorx.2.4.541

Palsgaard P, Gorin, FA \& Vorobyov, I (2018) Modelling interactions of urokinase plasminogen activator with amiloride and its derivatives. Biophys J 114(3):56a. https:/www.cell.com/biophysj/pdf/S0006-3495(17)31592-8.pdf

Pedrozo HA, Schwartz, Z, Robinson, M, Gomez, R, Dean, DD, Bonewald, LF \& Boyan, BD (1999) Potential mechanisms for the plasmin-mediated release and activation of latent transforming growth factor- $\beta 1$ from the extracellular matrix of growth plate chondrocytes1. Endocrinology 140(12):5806-5816.

https://doi.org/10.1210/endo.140.12.7224

Ploug M, Ostergaard, S, Gardsvoll, H, Kovalski, K, Holst-Hansen, C, Holm, A, Ossowski, L \& Dano, K (2001) Peptide-derived antagonists of the urokinase receptor. affinity maturation by combinatorial chemistry, identification of functional epitopes, and inhibitory effect on cancer cell intravasation. Biochemistry 40(40):12157-12168. https://doi.org/10.1021/bi010662g

Pyke C, Kristensen, P, Ralfkiaer, E, Grøndahl-Hansen, J, Eriksen, J, Blasi, F \& Danø, K (1991) Urokinase-type plasminogen activator is expressed in stromal cells and its receptor in cancer cells at invasive foci in human colon adenocarcinomas. The American journal of pathology 138(5):1059.

https://www.ncbi.nlm.nih.gov/pmc/articles/PMC1886028/

Rich IN, Worthington-White, D, Garden, OA \& Musk, P (2000) Apoptosis of leukemic cells accompanies reduction in intracellular $\mathrm{pH}$ after targeted inhibition of the $\mathrm{Na}+\mathrm{H}+$ exchanger. Blood 95(4):1427-1434. https://doi.org/10.1182/blood.V95.4.1427.004k48 $1427 \quad 1434$

Rockway TW \& Giranda, VL (2003) Inhibitors of the proteolytic activity of urokinase type plasminogen activator. Curr Pharm Des 9(19):1483-1498. https://doi.org/10.2174/1381612033454649

Rockway TW, Nienaber, V \& Giranda, VL (2002) Inhibitors of the protease domain of urokinase-type plasminogen activator. Curr Pharm Des 8(28):2541-2558. https://doi.org/10.2174/1381612023392676

Rømer J, Pyke, C, Lund, LR, Eriksen, J, Kristensen, P, Rønne, E, Høyer-Hansen, G, Danø, K \& Brünner, N (1994) Expression of UPA and its receptor by both neoplastic and stromal cells during xenograft invasion. Int J Cancer 57(4):553-560. https://doi.org/10.1002/ijc.2910570419

Roodbeen R, Paaske, B, Jiang, L, Jensen, JK, Christensen, A, Nielsen, JT, Huang, M, Mulder, FaA, Nielsen, NC \& Andreasen, PA (2013) Bicyclic peptide inhibitor of urokinase-type plasminogen activator: Mode of action. ChemBioChem 14(16):2179-2188. https://doi.org/10.1002/cbic.201300335

Rudolph MJ, Illig, CR, Subasinghe, NL, Wilson, KJ, Hoffman, JB, Randle, T, Green, D, Molloy, CJ, Soll, RM, Lewandowski, F, Zhang, M, Bone, R, Spurlino, JC, Deckman, IC, Manthey, C, Sharp, C, Maguire, D, Grasberger, BL, Desjarlais, RL \& Zhou, Z (2002) Design and synthesis of 4,5-disubstituted-thiophene-2amidines as potent urokinase inhibitors. Bioorg Med Chem Lett 12(3):491-495. http://dx.doi.org/10.1016/S0960-894X(01)00787-9 
Sa R, Fang, L, Huang, M, Li, Q, Wei, Y \& Wu, K (2014) Evaluation of interactions between urokinase plasminogen and inhibitors using molecular dynamic simulation and free-energy calculation. J Phy Chem A 118(39):91139119. https://doi.org/10.1021/jp5064319

Salajegheh A (2016) Urokinase plasminogen activator. In: Angiogenesis in health, disease and malignancy, Springer, Cham. https://doi.org/10.1007/978-3-319-28140-7 57

Santibanez JF (2017) Urokinase type plasminogen activator and the molecular mechanisms of its regulation in cancer. Protein Pept Lett 24(10):936-946. https://doi.org/10.2174/0929866524666170818161132

Sato S, Kopitz, C, Schmalix, WA, Muehlenweg, B, Kessler, H, Schmitt, M, Krüger, A \& Magdolen, V (2002) Highaffinity urokinase-derived cyclic peptides inhibiting urokinase/urokinase receptor-interaction: effects on tumor growth and spread. FEBS letters 528(1-3):212-216. https://doi.org/10.1016/S0014-5793(02)03311-2

Schuster V, Hügle, B \& Tefs, K (2007) Plasminogen deficiency. J Thromb Haemost 5(12):2315-2322. https://doi.org/10.1111/j.1538-7836.2007.02776.x

Schweinitz A, Steinmetzer, T, Banke, IJ, Arlt, MJE, Stürzebecher, A, Schuster, O, Geissler, A, Giersiefen, H, Zeslawska, E, Jacob, U, Krüger, A \& Stürzebecher, J (2004) Design of novel and selective inhibitors of urokinase-type plasminogen activator with improved pharmacokinetic properties for use as antimetastatic agents. J Biol Chem 279(32):33613-33622. https://doi.org/10.1074/jbc.M314151200

Setyono-Han B, Stürzebecher, J, Schmalix, WA, Muehlenweg, B \& Sieuwerts, AM (2005) Suppression of rat breast cancer metastasis and reduction of primary tumour growth by the small synthetic urokinase inhibitor WXUK1. Thromb Haemost 93:779-786. https://doi.org/10.1160/TH04-11-0712

Solis-Calero C, Zanatta, G, Do Ó Pessoa, C, Carvalho, HF \& Freire, VN (2018) Explaining urokinase type plasminogen activator inhibition by amino-5-hydroxybenzimidazole and two naphthamidine-based compounds through quantum biochemistry. Phys Chem Chem Phys 20(35):22818-22830. https://doi.org/10.1039/C8CP04315A

Spencer JR, Mcgee, D, Allen, D, Katz, BA, Luong, C, Sendzik, M, Squires, N \& Mackman, RL (2002) 4Aminoarylguanidine and 4-aminobenzamidine derivatives as potent and selective urokinase-type plasminogen activator inhibitors. Bioorg Med Chem Lett 12(15):2023-2026. https://doi.org/10.1016/S0960-894X(02)003128

Sperl S, Jacob, U, De Prada, NA, Stürzebecher, J, Wilhelm, OG, Bode, W, Magdolen, V, Huber, R \& Moroder, L (2000) (4-Aminomethyl) phenylguanidine derivatives as nonpeptidic highly selective inhibitors of human urokinase. Proc Natl Acad Sci 97(10):5113-5118. https://doi.org/10.1073/pnas.97.10.5113

Spraggon G, Phillips, C, Nowak, UK, Ponting, CP, Saunders, D, Dobson, CM, Stuart, DI \& Jones, EY (1995) The crystal structure of the catalytic domain of human urokinase-type plasminogen activator. Struct 3(7):681-691. https://doi.org/10.1016/S0969-2126(01)00203-9

Stepanova VV \& Tkachuk, VA (2002) Urokinase as a multidomain protein and polyfunctional cell regulator. Biochem 67(1):109-118. https://doi.org/10.1023/A:1013912500373

Stürzebecher J, Vieweg, H, Steinmetzer, T, Schweinitz, A, Stubbs, MT, Renatus, M \& Wikström, P (1999) 3Amidinophenylalanine-based inhibitors of urokinase. Bioorg Med Chem Lett 9(21):3147-3152. http://dx.doi.org/10.1016/S0960-894X(99)00541-7

Su SC, Lin, CW, Yang, WE, Fan, WL \& Yang, SF (2016) The urokinase-type plasminogen activator (uPA) system as a biomarker and therapeutic target in human malignancies. Expert Opin Ther Targets 20(5):551-566. https://doi.org/10.1517/14728222.2016.1113260

Subasinghe NL, Illig, C, Hoffman, J, Rudolph, MJ, Wilson, KJ, Soll, R, Randle, T, Green, D, Lewandowski, F, Zhang, M, Bone, R, Spurlino, J, Desjarlais, R, Deckman, I, Molloy, CJ, Manthey, C, Zhou, Z, Sharp, C, Maguire, D, Crysler, C \& Grasberger, B (2001) Structure-Based design, synthesis and SAR of a novel series of thiopheneamidine urokinase plasminogen activator inhibitors. Bioorg Med Chem Lett 11(11):1379-1382. http://dx.doi.org/10.1016/S0960-894X(01)00247-5

Sun G, Sui, Y, Zhou, Y, Ya, J, Yuan, C, Jiang, L \& Huang, M (2021) Structural basis of covalent inhibitory mechanism of TMPRSS2-related serine proteases by camostat. J Virol:JVI.-00861-00821. https://doi.org/10.1128/JVI.00861-21

Sun Q \& Sever, P (2020) Amiloride: A review. J Renin Angiotensin Aldosterone Syst 21(4):1470320320975893. https://doi.org/10.1177/1470320320975893

Tang L \& Han, X (2013) The urokinase plasminogen activator system in breast cancer invasion and metastasis. Biomed Pharmacother 67(2):179-182. https://doi.org/10.1016/j.biopha.2012.10.003

Towle MJ, Lee, A, Maduakor, EC, Schwartz, CE, Bridges, AJ \& Littlefield, BA (1993) Inhibition of urokinase by 4substituted benzo[g]thiophene-2-carboxamidines: An important new class of selective synthetic urokinase inhibitor. Cancer Res 53(11):2553. http://cancerres.aacrjournals.org/cgi/content/abstract/53/11/2553

Tsuda Y, Hidaka, K, Hojo, K \& Okada, Y (2021) Exploration of active site-directed plasmin inhibitors: Beyond tranexamic acid. Processes 9(2):329. https://doi.org/10.3390/pr9020329

Ulisse S, Baldini, E, Sorrenti, S \& D'armiento, M (2009) The urokinase plasminogen activator system: a target for anticancer therapy. Curr Cancer Drug Targets 9(1):32-71. https://doi.org/10.2174/156800909787314002

Van Der Burg MEL, Henzen-Logmans, SC, Berns, EMJJ, Van Putten, WLJ, Klijn, JGM \& Foekens, JA (1996) Expression of urokinase-type plasminogen activator (uPA) and its inhibitor PAI-1 in benign, borderline, malignant primary and metastatic ovarian tumors. Int J Cancer 69(6):475-479. https://doi.org/10.1002/(SICI)1097-0215(19961220)69:6<475::AID-IJC10>3.0.CO;2-0 
Vassalli JD \& Belin, D (1987) Amiloride selectively inhibits the urokinase-type plasminogen activator. FEBS letters 214(1):187-191. https://doi.org/10.1016/0014-5793(87)80039-X

Vassalli JD, Sappino, AP \& Belin, D (1991) The plasminogen activator/plasmin system. J Clin Invest 88(4):1067-1072. https://doi.org/10.1172/JCI115405

Venkatraj M, Messagie, J, Joossens, J, Lambeir, A-M, Haemers, A, Van Der Veken, P \& Augustyns, K (2012) Synthesis and evaluation of non-basic inhibitors of urokinase-type plasminogen activator (uPA). Biorg Med Chem 20(4):1557-1568. https://doi.org/10.1016/j.bmc.2011.12.040

Verner E, Katz, BA, Spencer, JR, Allen, D, Hataye, J, Hruzewicz, W, Hui, HC, Kolesnikov, A, Li, Y \& Luong, C (2001) Development of serine protease inhibitors displaying a multicentered short $(<2.3 \AA)$ hydrogen bond binding mode: Inhibitors of urokinase-type plasminogen activator and factor Xa. J Med Chem 44(17):27532771. https://doi.org/10.1021/jm0100638

Vidt DG (1981) Mechanism of action, pharmacokinetics, adverse effects, and therapeutic uses of amiloride hydrochloride, a new potassium-sparing diuretic. Pharmacotherapy: The Journal of Human Pharmacology and Drug Therapy 1(3):179-187. https://doi.org/10.1002/j.1875-9114.1981.tb02539.x

Warnock DG, Kusche-Vihrog, K, Tarjus, A, Sheng, S, Oberleithner, H, Kleyman, TR \& Jaisser, F (2014) Blood pressure and amiloride-sensitive sodium channels in vascular and renal cells. Nat Rev Nephrol 10(3):146-157. https://doi.org/10.1038/nrneph.2013.275

Wei L, Lun, Y, Zhou, X, He, S, Gao, L, Liu, Y, He, Z, Li, B \& Wang, C (2019) Novel urokinase-plasminogen activator inhibitor SPINK13 inhibits growth and metastasis of hepatocellular carcinoma in vivo. Pharmacol Res 143:7385. https://doi.org/10.1016/j.phrs.2019.03.009

Wendt MD, Geyer, A, Mcclellan, WJ, Rockway, TW, Weitzberg, M, Zhao, X, Mantei, R, Stewart, K, Nienaber, V \& Klinghofer, V (2004a) Interaction with the S1 $\beta$-pocket of urokinase: 8-heterocycle substituted and 6, 8disubstituted 2-naphthamidine urokinase inhibitors. Biorg Med Chem Lett 14(12):3063-3068. https://doi.org/10.1016/j.bmcl.2004.04.030

Wendt MD, Rockway, TW, Geyer, A, Mcclellan, W, Weitzberg, M, Zhao, X, Mantei, R, Nienaber, VL, Stewart, K \& Klinghofer, V (2004b) Identification of novel binding interactions in the development of potent, selective 2naphthamidine inhibitors of urokinase. Synthesis, structural analysis, and SAR of N-phenyl amide 6substitution. J Med Chem 47(2):303-324. https://doi.org/10.1021/jm0300072

Wermuth CG (2006) Selective optimization of side activities: the SOSA approach. Drug Discov Today 11(3-4):160164. https://doi.org/10.1016/S1359-6446(05)03686-X

West CW, Adler, M, Arnaiz, D, Chen, D, Chu, K, Gualtieri, G, Ho, E, Huwe, C, Light, D, Phillips, G, Pulk, R, Sukovich, D, Whitlow, M, Yuan, S \& Bryant, J (2009) Identification of orally bioavailable, non-amidine inhibitors of urokinase plasminogen activator (uPA). Biorg Med Chem Lett 19(19):5712-5715. https://doi.org/10.1016/j.bmcl.2009.08.008

Wu G, Mazzitelli, BA, Quek, AJ, Veldman, MJ, Conroy, PJ, Caradoc-Davies, TT, Ooms, LM, Tuck, KL, Schoenecker, JG, Whisstock, JC \& Law, RHP (2019) Tranexamic acid is an active site inhibitor of urokinase plasminogen activator. Blood advances 3(5):729-733. https://doi.org/10.1182/bloodadvances.2018025429

Wun TC, Ossowski, L \& Reich, E (1982) A proenzyme form of human urokinase. J Biol Chem 257(12):7262-7268. https://doi.org/10.1016/S0021-9258(18)34566-6

Wyganowska-Świątkowska M \& Jankun, J (2015) Plasminogen activation system in oral cancer: Relevance in prognosis and therapy. Int J Oncol 47(1):16-24. https://doi.org/10.3892/ijo.2015.3021

Xing RH \& Rabbani, SA (1996) Overexpression of urokinase receptor in breast cancer cells results in increased tumor invasion, growth and metastasis. Int J Cancer 67(3):423-429. https://doi.org/10.1002/(SICI)10970215(19960729)67:3<423::AID-IJC18>3.0.CO;2-8

$\mathrm{Xu}$ P, Andreasen, PA \& Huang, M (2017) Structural principles in the development of cyclic peptidic enzyme inhibitors. Int J Biol Sci 13(10):1222-1233. https://doi.org/10.7150/ijbs.21597

Xue G, Xie, X, Zhou, Y, Yuan, C, Huang, M \& Jiang, L (2020) Insight to the residue in P2 position prevents the peptide inhibitor from being hydrolyzed by serine proteases. Biosci, Biotechnol, Biochem 84(6):1153-1159. https://doi.org/10.1080/09168451.2020.1723405

Yang J-L, Seetoo, D-Q, Wang, Y, Ranson, M, Berney, CR, Ham, JM, Russell, PJ \& Crowe, PJ (2000) Urokinase-type plasminogen activator and its receptor in colorectal cancer: Independent prognostic factors of metastasis and cancer-specific survival and potential therapeutic targets. Int J Cancer 89(5):431-439. https://doi.org/10.1002/1097-0215(20000920)89:5<431::AID-IJC6>3.0.CO;2-V

Yuan C, Guo, Z, Yu, S, Jiang, L \& Huang, M (2021) Development of inhibitors for uPAR: blocking the interaction of UPAR with its partners. Drug Discovery Today 26(4):1076-1085. https://doi.org/10.1016/j.drudis.2021.01.016

Zeslawska E, Schweinitz, A, Karcher, A, Sondermann, P, Sperl, S, Stürzebecher, J \& Jacob, U (2000) Crystals of the urokinase type plasminogen activator variant $\beta c$-uPA in complex with small molecule inhibitors open the way towards structure-based drug design. J Mol Biol 301(2):465-475. https://doi.org/10.1006/jmbi.2000.3966

Zhang H, Peng, C, Huang, H, Lai, Y, Hu, C, Li, F \& Wang, D (2018) Effects of amiloride on physiological activity of stem cells of human lung cancer and possible mechanism. Biochem Biophys Res Commun 504(1):1-5.

https://doi.org/10.1016/j.bbrc.2018.06.138 
Zhao B, Xu, P, Jiang, L, Paaske, B, Kromann-Hansen, T, Jensen, JK, Sørensen, HP, Liu, Z, Nielsen, JT \& Christensen, A (2014) A cyclic peptidic serine protease inhibitor: increasing affinity by increasing peptide flexibility. PLoS One 9(12):e115872. https://doi.org/10.1371/journal.pone.0115872

Zhao G, Yuan, C, Wind, T, Huang, Z, Andreasen, PA \& Huang, M (2007) Structural basis of specificity of a peptidyl urokinase inhibitor, upain-1. J Struct Biol 160(1):1-10. https://doi.org/10.1016/j.jsb.2007.06.003

Zhu C, Jiang, L, Xu, J, Ren, A, Ju, F \& Shu, Y (2020) The urokinase-type plasminogen activator and inhibitors in resectable lung adenocarcinoma. Pathology - Research and Practice 216(4):152885. https://doi.org/10.1016/j.prp.2020.152885

Zhu M, Gokhale, VM, Szabo, L, Munoz, RM, Baek, H, Bashyam, S, Hurley, LH, Von Hoff, DD \& Han, H (2007) Identification of a novel inhibitor of urokinase-type plasminogen activator. Mol Cancer Ther 6(4):1348-1356. https://doi.org/10.1158/1535-7163.MCT-06-0520 